\title{
Inactivation of C4orf26 in Toothless Placental Mammals
}

Mark S. Springer ${ }^{\mathrm{a}^{\mathrm{k}}}$, James Starrett ${ }^{\mathrm{a}, \mathrm{b}}$, Phillip A. Morin ${ }^{\mathrm{c}, \mathrm{d}}$, Agnese Lanzetti ${ }^{\mathrm{a}, \mathrm{b}}$, Cheryl Hayashi $^{\mathrm{a}}$, John Gatesy ${ }^{\mathrm{a}}$

${ }^{a}$ Department of Biology, University of California, Riverside, CA 92521, USA

${ }^{\mathrm{b}}$ Department of Biology, San Diego State University, San Diego, CA 92182, USA

${ }^{\mathrm{c}}$ Southwest Fisheries Science Center, National Marine Fisheries Service, National

Oceanic and Atmospheric Administration, La Jolla, CA 92037, USA

${ }^{\mathrm{d}}$ Scripps Institution of Oceanography, University of California, San Diego, La Jolla, CA 92037, USA

*Corresponding author.

E-mail address: mark.springer@ucr.edu (M.S. Springer). 
Abstract. Previous studies have reported inactivated copies of six enamel-related genes (AMBN, AMEL, AMTN, ENAM, KLK4, MMP20) and one dentin-related gene (DSPP) in one or more toothless vertebrates and/or vertebrates with enamelless teeth, thereby providing evidence that these genes are enamel or tooth-specific with respect to their critical functions that are maintained by natural selection. Here, we employ available genome sequences for edentulous and enamelless mammals to evaluate the enamel specificity of four genes (WDR72, SLC24A4, FAM83H, C4orf26) that have been implicated in amelogenesis imperfecta, a condition in which proper enamel formation is abrogated during tooth development. Coding sequences for WDR72, SCL24A4, and FAM83H are intact in four edentulous taxa (Chinese pangolin, three baleen whales) and three taxa (aardvark, nine-banded armadillo, Hoffmann's two-toed sloth) with enamelless teeth, suggesting that these genes have critical functions beyond their involvement in tooth development. By contrast, genomic data for $C 4$ orf 26 reveal inactivating mutations in pangolin and bowhead whale as well as evidence for deletion of this gene in two minke whale species. Hybridization capture of exonic regions and PCR screens provide evidence for inactivation of C4orf 26 in eight additional baleen whale species. However, C4orf26 is intact in all three species with enamelless teeth that were surveyed, as well as in 95 additional mammalian species with enamel-capped teeth. Estimates of selection intensity suggest that $\mathrm{dN} / \mathrm{dS}$ ratios on branches leading to taxa with enamelless teeth are similar to the $\mathrm{dN} / \mathrm{dS}$ ratio on branches leading to taxa with enamel-capped teeth. Based on these results, we conclude that $C 4$ orf 26 is tooth-specific, but not enamel-specific, with respect to its essential functions that are maintained by natural selection. A caveat is that an alternative splice site variant, which translates exon 3 in a different reading frame, is putatively functional in Catarrhini and may have evolved an additional role in this primate clade.

Keywords:

\section{Cetacea}

C4orf26

Mysticeti 
Pholidota

Pseudogenes

Tooth genes

\section{Introduction}

The evolution of teeth is one of the hallmark features of jawed vertebrates (gnathostomes). Teeth and jaws are a formidable combination for food acquisition and processing. Nevertheless, numerous lineages of vertebrates have secondarily lost their teeth or at least the outer enamel covering of their teeth. Nature's replicated experiments with edentulism (=toothlessness) and enamel loss include birds, turtles, echidnas, pangolins, baleen whales, pygmy and dwarf sperm whales, narwhals, xenarthrans (anteaters, sloths, armadillos), aardvarks, and Steller's sea cow (Davit-Béal et al., 2009). Recent studies have demonstrated that six genes involved in enamel formation ( $A M B N$, AMELX, AMTN, ENAM, KLK4, MMP20) and one gene involved in dentin formation $(D S P P)$ have been inactivated in one or more of these edentulous and/or enamelless forms (Deméré et al., 2008; McKnight and Fisher, 2009; Meredith et al., 2009, 2011a, 2013, 2014; Gasse et al., 2012; Kawasaki et al., 2014; Delsuc et al., 2015; Springer et al., 2015). At the same time, all of these genes are expressed outside of tooth development in mammals with enamel-capped teeth (Qin et al., 2002, 2003; Ogbureke and Fisher, 2004, 2005, 2007; Ryu et al., 2005; Deutsch et al., 2006; Turk et al., 2006; Greenlee et al., 2007; Haze et al., 2007; Caton and Tucker, 2009; Wheeler et al., 2009; Seiz et al., 2010;

Fuchs et al., 2012; Atsawasuwan et al., 2013). However, the inactivation of these genes in edentulous/enamelless mammals provides evidence that these genes are tooth specific with respect to their essential functions that are maintained by natural selection (Meredith et al., 2014). Reports of gene inactivation in toothless and enamelless vertebrates reinforce knockout/knockin studies in mice and accounts of humans with non-syndromic amelogenesis imperfecta (AI) and dentinogenesis imperfecta (DI) that have suggested tooth-specific roles for these genes (Gibson et al., 2001; Fukumoto et al., 2004; Hart et al., 2004; Simmer et al., 2009; Smith et al., 2009; Chan et al., 2011; Wang et al., 2013; Kawasaki et al., 2014). 
AI results from the failure of normal amelogenesis and is associated with a variety of enamel defects. Mutated genes in non-syndromic AI include genes that encode enamel matrix proteins (AMELX, AMBN, AMTN, ENAM) and proteases $(K L K 4, M M P 20)$ that are associated with normal amelogenesis in placental mammals, with the caveat that $K L K 4$ is found only in boreoeutherian placental mammals, where it may be associated with more rapid tooth eruption (Kawasaki et al., 2014). Other candidate genes for non-syndromic AI include FAM83H, WDR72, C4orf26, and SLC24A4 (Kim et al., 2008; El-Sayed et al., 2009; Parry et al., 2012, 2013; Wang et al., 2014). Additional AI genes are associated with syndromes that affect non-dental phenotypes (NHS, CNNM4, FAM20A, ITGA6, ITGB4, ITGB6, LAMA3, LAMB3, LAMC2, COL17A1, ITGA6, ITGB4) (Wang et al., 2014).

Here, we test the hypotheses that FAM83H, WDR72, C4orf26, and SLC24A4 are tooth-specific genes with respect to their essential functions that are maintained by natural selection by surveying the available genomes of four edentulous species (Chinese pangolin, two minke whales, bowhead whale) and three enamelless species (aardvark, Hoffmann's two-toed sloth, nine-banded armadillo) for intact versus inactivated copies of these genes. Inferences based on these surveys were extended with exon capture experiments, PCR screens, and selection analyses.

\section{Materials and methods}

\subsection{Database mining}

C4orf26, FAM83H, SLC24A4, and WDR72 were used as key words to search for mRNA sequences in GenBank. Nucleotide blast searches were performed against NCBI's whole-genome shotgun contigs using megablast and coding sequences from the same taxon when available or from the closest available relative as query (e.g., carnivorans for Chinese pangolin, odontocetes for mysticetes). We targeted the genomes of three edentulous taxa (Manis pentadactyla [Chinese pangolin], Balaenoptera acutorostrata [common minke whale], Balaenoptera bonaerensis [Antarctic minke whale]), three taxa with enamelless teeth (Orycteropus afer [aardvark], Choloepus hoffmanni [Hoffmann's 
two-toed sloth], Dasypus novemcinctus [nine-banded armadillo]), and representative outgroups with enamel-capped teeth, i.e., one or more afrotherians (Loxodonta africana [African elephant], Chrysochloris asiatica [Cape golden mole], Trichechus manatus [manatee], Elephantulus edwardii [elephant shrew]) for Orycteropus and xenarthrans, one or more odontocetes (toothed whales) and Bos taurus (cow) for the three baleen whales, and representative carnivorans (Felis catus [cat], Canis lupus familiaris [dog], Odobenus rosmarus [walrus]) for Manis. We note that enamel loss is hypothesized to have occurred independently in the two xenarthrans, $C$. hoffmanni and D. novemcinctus (Meredith et al. 2009). Retrieved contigs or relevant portions thereof were imported into Geneious 7.1.9 (Kearse et al., 2012) and manually annotated by aligning exons from Homo sapiens reference sequences against the individual contigs. In addition, the genome of the edentulous Balaena mysticetus (bowhead whale) (Keane et al., 2015) was imported into Geneious and queried with discontiguous megablast using sequences from other cetaceans. Coding sequences were manually inspected for inactivating mutations including premature stop codons, frameshift mutations, start codon missense mutations, and altered splice sites at intron boundaries. The latter were identified following the AG (acceptor splice site)/GT (donor splice site) rule. Discontiguous megablast searches against the NCBI sequence-read archive (SRA) were performed with query sequences from Chinese pangolin (Manis pentadactyla) to confirm inactivating mutations in C4orf26 in this species.

\subsection{Hybridization capture and next generation sequencing}

Genomic DNA from four cetartiodactyl taxa (Choeropsis liberiensis [pygmy hippopotamus; New York Zoological Society = NYZS, G. Amato], Delphinapterus leucas [beluga; NYZS, G. Amato], Balaenoptera physalus [fin whale; NYZS, H. Rosenbaum], B. bonaerensis [Antarctic minke whale; Southwest Fisheries Science Center = SWFSC Z23603 from South Australian Museum, Adelaide, Australia = SAM M15375]) was extracted using the DNeasy Blood and Tissue kit (Qiagen). Three $\mu \mathrm{g}$ of genomic DNA were sheared into fragments with a highest concentration at 180 to 190 bp using a Bioruptor (Diagenode), followed by treatment with PreCR Repair Mix (New 
England Biolabs). The SureSelect ${ }^{\mathrm{XT}}$ Target Enrichment System for Illumina Paired-End Sequencing Library kit (Agilent) was used for library construction and target enrichment. Target enrichment for capture probes, including the coding exons of C4orf26 and FAM83H, was done with a custom-designed SureSelect biotinylated RNA library. Probes, including $60 \mathrm{bp}$ overhangs of intron sequence at both the 5' and 3 ' ends, were compiled from cetacean genome sequences (Tursiops truncatus, Orcinus orca). The fasta file of exon+flanking sequences was entered into the Agilent SureDesign algorithm to generate 120-base long oligomers with sufficient overlap that each nucleotide position in the compiled database was present, on average, in five different oligos. Paired-end sequencing $(2 \times 100)$ of target-enriched libraries was performed on an Illumina HiSeq 2500 platform at the UC Riverside Institute for Integrative Genome Biology Genomics Core. Per-base quality distributions of de-multiplexed fastq files were visualized for both read pair files using FastQC v.0.10.0 (http://www.bioinformatics.babraham.ac.uk/projects/fastqc/) with the no-group setting. Based on these results, FASTX-Toolkit v.0.0.13.2 (http://hannonlab.cshl.edu/fastx_toolkit/index.html) was used to trim the first three bases and the last base, which resulted in 97 bp reads. Reads with all but three identical bases or a quality score below 30 at any base position were then filtered out. PRINSEQ lite v.0.20.4 (Schmieder and Edwards, 2011) was used to find read pairs that passed the filtering conditions. These read pairs were then interleaved into a single file using the ShuffleFastq script in RACKJ v.0.95

(http://rackj.sourceforge.net/Scripts/index.html\#ShuffleFastq). Fastq files were imported into Geneious. Individual reads were mapped to reference ("probe") sequences and consensus sequences were assembled with a matching threshold of $85 \%$. Accession numbers for new sequences are KT924421-KT924422 (C4orf26) and KT932358KT932361 (FAM83H).

\subsection{PCR and Sanger sequencing}

To extend inferences based on genome sequences, PCR amplifications of C4orf26 were executed to determine the phylogenetic distribution of inactivating mutations in Mysticeti (baleen whales). Three segments of the C4orf 26 gene were targeted: exon 1, 
exon 3, and a region that spans the deletion of the C4orf26 gene in minke whale (see Results, below). Eleven mysticete species were sampled: Balaena mysticetus - SWFSC Z6985 from North Slope Borough, Barrow, Alaska, USA; Eubalaena glacialis - SWFSC Z13086 from Northeast Fisheries Science Center; Eubalaena australis - SWFSC Z18928 from SAM M16470; Caperea marginata - SWFSC Z26572 from SAM ABTC27074; Eschrichtius robustus - SWFSC Z13090 from the Marine Mammal Center, Sausalito, California, USA = TMMC, P. Clapham; Balaenoptera acutorostrata - SWFSC Z13091 from TMMC; Balaenoptera borealis - SWFSC Z2515; Balaenoptera brydei-SWFSC Z16039; Balaenoptera musculus - (two individuals) SWFSC Z4502 and SWFSC Z11989; Balaenoptera physalus - NYZS, H. Rosenbaum; Megaptera novaeangliae SWFSC Z11727.

PCR primers were as follows (5' to 3'):

exon1_F - CCGCAGGCCCTAATCCCTGTGGTCCACTATGC

exon1_R - CACATAGCTAGGGCTGAGACTAGGACCTTCCG exon3_F - CTGGGCAGTTCTCTCAAACATGCTTTGAGACTC exon3_R - TTTCCAGCCCAATAGTTTTAGTTTAGTAACTG minke_deletion_F - CGTCAGTTGCAGACTTGCCAGCAAAGTGTACTC minke_deletion_R - CCACTGGCAGGAGTTAGAAACATCAGCATCAC). For each segment of C4orf26, PCR reactions were performed in $50 \mu \mathrm{l}$ volumes and contained $67 \mathrm{mM}$ Tris, $3 \mathrm{mM} \mathrm{MgCl} 2,16.6 \mathrm{mM}$ (NH4)2SO4, $200 \mu \mathrm{M}$ dNTPs, $1 \mu \mathrm{M}$ of each primer, and $1 \mathrm{U}$ of Taq polymerase (Invitrogen). Amplifications included an initial 2 min denaturation phase $\left(94^{\circ} \mathrm{C}\right)$; followed by 45 cycles with 1 min denaturation $\left(94^{\circ} \mathrm{C}\right), 1$ min annealing $\left(55^{\circ} \mathrm{C}\right.$ for exon $1,52^{\circ} \mathrm{C}$ for exon 3 , and $60^{\circ} \mathrm{C}$ for minke deletion), 1 min extension $\left(72^{\circ} \mathrm{C}\right)$; and a final 2 min elongation phase $\left(72^{\circ} \mathrm{C}\right)$. PCR products were cleaned and concentrated using Montage PCR Centrifugal Filter Devices (Millipore). Exon 1 and exon 3 amplicons were Sanger sequenced in both directions using the PCR primers and utilized in phylogenetic analyses and estimates of selection intensity. Accession numbers for new sequences are KT923113-KT923117. PCR amplifications of the genomic region that spans the deletion point of C4orf26 in minke whale were used to screen for this large deletion in other mysticete species. The deletion in minke whale is $\sim 28 \mathrm{~kb}$ relative to 
bowhead and PCR is expected to fail for species that retain the two exons. Amplicons were Sanger sequenced in one direction using the 'deletion_F' primer and match to the targeted region in the minke whale genome was confirmed by nucleotide megablast searches (NCBI).

\subsection{Phylogenetic analyses}

Sequences were aligned with MAFFT (Katoh et al., 2002) and MUSCLE (Edgar, 2005 ) in Geneious with minor modifications by eye. Ambiguous regions of the C4orf26 gene were excluded prior to phylogenetic and selection analyses. Phylogenetic analyses were performed with RAxML 8.1.1 (Stamatakis, 2006) on CIPRES Science Gatesy V 3.3 (Miller et al., 2010), which implements a GTR $+\Gamma$ model of sequence evolution (i.e., GTRGAMMA option in RAxML) that was used for individual bootstrap pseudoreplicates and the search for the best tree. Rapid bootstrap analyses (Stamatakis et al., 2008) were performed with 500 pseudoreplicates. Bootstrap analyses and a search for the best ML tree were performed in a single run.

\subsection{Selection analyses}

Branch analyses that estimated the ratio $(\omega)$ of the non-synonymous substitution rate $(\mathrm{dN})$ to the synonymous substitution rate $(\mathrm{dS})$ were performed with the Codeml program in PAML 4.5 (Yang, 2007). Selection analyses were performed with a dataset comprising 18 C4orf26 sequences including sequences from five edentulous species (Manis pentadactyla, Balaena mysticetus, Eubalaena australis, E. glacialis, Balaenoptera musculus), three species with enamelless teeth (Orycteropus afer, Choloepus hoffmanni, Dasypus novemcinctus), and ten closely related outgroup taxa with enamel-capped teeth. Analyses were run with two different codon frequency models $($ CodonFreq $=1[\mathrm{CF} 1]$ and CodonFreq $=2[\mathrm{CF} 2]) . \mathrm{CF} 1$ employs equilibrium codon frequencies that are calculated from the average nucleotide frequencies of the sequences, whereas CF2 employs equilibrium codon frequencies that are calculated from the average nucleotide frequencies at each of three codon positions. We used a species tree with 
interordinal and interfamilial relationships as in Meredith et al. (2011b) and intrafamilial relationships within Balaenidae as in McGowen et al. (2009). Branch analyses were performed with Model 1 (one dN/dS ratio) and three additional models (Models 2-4) with two to five dN/dS categories for branches leading to taxa with enamel-capped teeth, branches where enamel was lost, and branches where teeth were lost (pangolin branch, stem Mysticeti branch) or are absent (crown Mysticeti) (Meredith et al., 2009).

Alignment positions with frameshift insertions were removed prior to Codeml analyses to prevent disruption of the proper reading frame. In addition, stop codons were recoded as missing data as is required to perform $\mathrm{dN} / \mathrm{dS}$ analyses with Codeml. The results of different branch analyses were compared with likelihood ratio tests. Tests for multiple comparisons were adjusted with a Holm-Bonferroni correction (Holm, 1979; Gaetano, 2013).

\section{Results}

\subsection{WDR72}

Complete coding sequences (exons 2-20) were recovered for representative taxa with enamel-capped teeth, as well as for all three edentulous mysticetes (Balaena mysticetus, Balaenoptera acutorostrata, Balaenoptera bonaerensis) for which assembled genome sequences are available. Among other edentulous/enamelless taxa, nearly complete coding sequences were recovered for aardvark (Orycteropus afer), sloth (Choloepus hoffmanni), and armadillo (Dasypus novemcinctus) (Table 1, Supplementary Alignment File 1). The sequence for pangolin (Manis pentadactyla) was less complete, but included the first 14 exons. In all of the above cases the missing exons are not spanned by flanking sequences that occur on a single genomic contig, which suggests that the relevant regions are missing from the genome assemblies due to inadequate sequencing depth and/or assembly. All of the recovered coding sequences in edentulous and enamelless taxa are putatively functional based on the absence of frameshift mutations and premature stop codons (Supplementary Alignment File 1). Moreover, all

of the acceptor and donor splice site sequences are intact and exhibit the canonical "AG" 
and "GT" motifs, respectively, where they abut exons. The RAxML tree for WDR72 (Fig. S1) is consistent with the monophyly of the four major clades of placental mammals (Afrotheria, Xenarthra, Laurasiatheria, Euarchontoglires) (Madsen et al., 2001; Murphy et al., 2001a, b; Scally et al., 2001).

\subsection{SLC24A4}

Complete coding sequences (exons 1-17) were recovered for Balaena mysticetus, Choloepus hoffmanni, and Dasypus novemcinctus. Part of exon 7 is missing for Balaenoptera acutorostrata, and we recovered 16 of 17 exons for the remaining taxa (Balaenoptera bonaerensis [missing exon 7], Manis pentadactyla [missing exon 1], Orycteropus afer [missing exon 3]) (Table 1). In all of these cases, the missing exons are not spanned by single genomic contigs and their absence is consistent with incomplete genome assemblies. For example, we recovered exons 2 and 4 from $O$. afer, but did not recover exon 3. If exons 2 and 4 were recovered from the same contig this might suggest deletion of exon 3 from the genome. However, exons 2 and 4 were recovered from two different contigs, 148144 (ALYB01148144) and 148158 (ALYB01148158), respectively, so that the genome assembly spanning the region that contains exons 2-4 is incomplete. Exons 2 and 4 are separated by $\sim 157 \mathrm{~kb}$ in another afrotherian (African elephant) with an assembled sequence that spans all of $S L C 24 A 4$. All of the recovered coding sequences are intact (i.e., no frameshift mutations or premature stop codons; Supplementary Alignment File 2). Further, all of the splice sites are canonical ("AG" for acceptor splice sites, "GT" for donor splice sites). The RAxML tree for SLC24A4 is consistent with the monophyly of Afrotheria, Xenarthra, Laurasiatheria, and Euarchontoglires (Fig. S2).

\subsection{FAM83H}

All four protein-coding exons (1-4) were recovered for Balaena mysticetus, Orycteropus afer, and Choloepus hoffmanni. Complete exon sequences for exons 1 and 3, as well as partial sequences for exons 2 and 4, were recovered for Dasypus novemcinctus. Exons 1-3 and partial sequences for exon 4 were recovered for Balaenoptera 
acutorostrata, Balaenoptera bonaerensis, and Manis pentadactyla (Table 1). The missing regions of exon 2 and 4 in the above taxa are not spanned by genomic contigs and appear to be missing from the genome assemblies. This is confirmed for Balaenoptera by exon capture experiments that recovered complete coding sequences for $B$. bonaerensis and its congener $B$. physalus (fin whale). All of the recovered protein-coding sequences are intact in edentulous and enamelless taxa and there are no stop codons or frameshift mutations (Supplementary Alignment File 3). In addition, all splice sites are canonical "AG" (acceptor) and "GT" (donor). The RAxML tree for FAM83H is consistent with the monophyly of Afrotheria, Xenarthra, Laurasiatheria, and Euarchontoglires (Fig. S3). Odontoceti and Mysticeti are reciprocally monophyletic, and the two sequences for $B$. bonaerensis (NCBI genome, exon capture) group together.

\subsection{C4orf 26}

The primary transcript variant of C4orf26 (NM_178497.3) (Parry et al., 2012) contains two exons, 1 and 3, both of which were recovered in representative taxa with enamel-capped teeth (elephant, human, dog, cow) as well as in five of seven edentulous or enamelless taxa for which genome sequences are available. Coding sequences for all three enamelless taxa (Orycteropus afer, Choloepus hoffmanni, Dasypus novemcinctus), like those of taxa with enamel-capped teeth, are intact and have start codons, stop codons, and canonical splice site sequences. By contrast, sequences for the edentulous taxa Balaena mysticetus (bowhead whale) and Manis pentadactyla (Chinese pangolin) contain inactivating mutations including start codon mutations (M. pentadactyla, B. mysticetus), numerous frameshift mutations (M. pentadactyla), and mutations in the donor splice site of intron 1 ("GT" to "GG" in B. mysticetus, deletion of splice site in M. pentadactyla) (Fig. 1). Both exons are missing from the genomes of the two minke whales (Balaenoptera acutorostrata, B. bonaerensis), which like Balaena mysticetus are edentulous and have baleen instead of teeth. Scaffold109_contig12 (ATDI01091756) of B. acutorostrata includes 5' and 3' flanking sequences that span the missing exons, which suggests that these protein-coding exons were completely deleted from the genome of this taxon (Fig. 2). The results of exon-capture hybridization experiments confirm that 
C4orf26 exons are missing from the genome of B. bonaerensis, as well as from the genome of the fin whale (Balaenoptera physalus). Specifically, there were only five short reads from $B$. bonaerensis and one short read from B. physalus that assembled to two C4orf26 exon reference sequences from Orcinus orca (killer whale). This low coverage is consistent with expectations based on sequencing errors that result in barcode misassignments. By contrast, 20165 short reads from the pygmy hippopotamus (Choeropsis liberiensis) assembled to the same reference sequences even though the killer whale is more closely related to baleen whales than to hippopotamus. Furthermore, Table 2 shows that two other tooth genes (ENAM, FAM83H), which are present in the assembled genome of $B$. acutorostrata, were recovered with high coverage in two congeners, $B$. bonaerensis and B. physalus, using reference sequences from delphinid genomes $(O$. orca or Tursiops truncatus [bottlenose dolphin]).

The phylogenetic distributions of inactivating mutations in Mysticeti were explored via PCR screens of three different segments of the C4orf26 gene: exon 1, exon 3 , and a third segment that spans the region where exons 1 and 3 were deleted from the minke whale genome (Fig. 2). Eleven mysticete species that represent all extant genera were surveyed to determine when the deletion of C4orf 26 occurred and to test whether inactivating substitutions observed in Balaena mysticetus (Fig. 1) originated in the common ancestor of all extant mysticetes.

Protein-coding exons 1 and 3 amplified for four species. Three of these were balaenids (Eubalaena australis, E. glacialis, Balaena mysticetus); the PCR sequence from bowhead confirmed the two inactivating substitutions in the Balaena genome (Fig. 1). Both Eubalaena species shared the "ATG" to "TTG" mutation found in the start codon of C4orf 26 from Balaena, but the donor splice site sequence of intron 1 in Eubalaena spp. is canonical ("GT") in contrast to the condition observed in Balaena ("GG"). Additionally, there is a mutation to a stop signal at codon position 35 of the C4orf26 gene (exon 3) in E. australis; this codon shows a change from the primitive condition ("CAA" glutamine) to "TAA" stop and is heterozygous ("YAA") in this individual. Balaenoptera musculus (blue whale; family Balaenopteridae) was the fourth species that amplified with exon 1 and exon 3 primer pairs, but sequences from this species lack the two inactivating substitutions observed in balaenids. Instead, the two 
blue whale individuals that were sampled share two different inactivating substitutions in the C4orf26 gene. The start codon is mutated at the second position ("ATG" to "ACG"; homozygous in SWFSC Z4502, heterozygous "AYG” in SWFSC Z11989), and the donor splice site of intron 1 is altered from "GT" to "AT" (Fig. 1). Given that Eubalaena + Balaena and B. musculus represent Balaenidae and Plicogulae, the basal clades of extant Mysticeti (Deméré et al., 2008), the C4orf26 exonic sequences imply absence of inactivating mutations in the last common ancestor of extant baleen whales. Caperea marginata (pygmy right whale; Neobalaenidae), Eschrichtius robustus (gray whale; Eschrichtiidae), and five balaenopterids (including the minke whale, B. acutorostrata) did not amplify with the exon 1 and exon 3 primers.

The segment of the genome that spans the deletion of exons 1 and 3 in minke whale did not amplify in any of the four species that generated PCR products for the two protein-coding exons (see above), as would be expected for a region of nearly $30 \mathrm{~kb}$. Caperea, the only extant representative of Neobalaenidae, also did not amplify, suggesting that the C4orf 26 gene of this species has a distinctive genomic conformation relative to other baleen whale species. The minke whale deletion region was successfully amplified from the remaining six species sampled here, Eschrichtius (Eschrichtiidae) and five representatives of Balaenopteridae, confirming that excision of the C4orf26 gene dates to the common ancestor of Balaenopteroidea (Balaenopteridae + Eschrichtiidae), $\sim 14$ million years ago, or more, according to molecular clock estimates (McGowen et al., 2009; Steeman et al. 2009; Marx and Fordyce, 2015). For 10 of 11 mysticete species in our PCR screen, evidence for inactivating substitutions (four species) or deletion of exons 1 and 3 (six species) was confirmed, but we found no evidence for common inactivating mutations that map to the last common ancestor of crown mysticetes.

The finding that $C 4$ orf 26 is putatively functional in representative species with enamelless teeth but inactivated or completely lost in edentulous species suggests that this gene is tooth-specific, but not enamel-specific. If C4orf26 is tooth-specific, but not enamel-specific, it should remain under selective constraints in enamelless taxa but not edentulous taxa. To test this hypothesis, we performed a series of $\mathrm{dN} / \mathrm{dS}$ branch analyses on C4orf 26 sequences for representative taxa with enamel-capped teeth, all three enamelless forms (Orycteropus afer, Choloepus hoffmanni, Dasypus novemcinctus), and 
five edentulous species (Balaena mysticetus, Eubalaena australis, E., glacialis, Balaenoptera musculus, Manis pentadactyla). We performed analyses with up to five different $\mathrm{dN} / \mathrm{dS}$ categories for different branches. First, we compared a model with one $\mathrm{dN} / \mathrm{dS}$ category for all branches (Model 1) to a model with four branch categories (Model 2), one category for branches leading to taxa with teeth (enamel-capped or enamelless) and three additional categories for the M. pentadactyla, stem Mysticeti, and crown Mysticeti branches. The dN/dS values for M. pentadactyla and the stem mysticete branches were both elevated above 1.0 (Table 3), and the model with four branch categories was significantly better $(\mathrm{p}<0.005$ than the model with one branch category. Selection analyses yielded $\mathrm{dN} / \mathrm{dS}$ values for crown mysticete branches that are below 1.0 with both codon frequency models $(\mathrm{CF} 1=0.73, \mathrm{CF} 2=0.71)$, but these values are not significantly different from 1.0 as is expected for branches that post-date the loss of teeth on the stem mysticete branch (Meredith et al., 2011). By contrast with branches in crown Mysticeti, $\mathrm{dN} / \mathrm{dS}$ values are both $>1.0$ on the pangolin and stem mysticete branches that are transitional for tooth loss (Table 3 ). Values of $\mathrm{dn} / \mathrm{dS}>1.0$ suggest that positive selection may have favored amino acid changes in C4orf26 prior to its eventual inactivation. We therefore compared our model with four branch categories and positive selection (Model 2) to a simpler model (Model 3) with one $\mathrm{dN} / \mathrm{dS}$ category for branches leading to taxa with teeth and a second category with $\mathrm{dN} / \mathrm{dS}=1.0$ (neutral evolution) for transitional branches where teeth were lost (M. pentadactyla, stem Mysticeti) and for branches where teeth are absent (crown Mysticeti) (Meredith et al., 2011). There was no statistical difference between the model that allowed for positive selection (Model 2) and the model that enforced neutral evolution (Model 3) on the transitional (M. pentadactyla, stem Mysticeti) and fully edentulous branches, irrespective of whether the $M$. pentadactyla, stem Mysticeti, and crown Mysticeti branch categories were fixed simultaneously at 1.0 or whether each of these branch categories was fixed at 1.0, one at a time, while allowing the other two categories to retain estimated $\mathrm{dN} / \mathrm{dS}$ values (Table 3). However, the model with two branch categories is significantly better $(\mathrm{p}<0.001)$ than the model with a single dN/dS category (Table 1). Finally, we compared the two-category model (Model 3) with a five-category model (Model 4) wherein each of the three branches leading to taxa with enamelless teeth (O. afer, C. hoffmanni, D. novemcinctus) 
was allowed to have its own $\mathrm{dN} / \mathrm{dS}$ value (enamel loss occurred independently in the two xenarthrans, C. hoffmanni and D. novemcinctus [Meredith et al., 2009]). There was no statistical difference between these models, suggesting that $\mathrm{dN} / \mathrm{dS}$ values on branches where enamel was lost are indistinguishable from $\mathrm{dN} / \mathrm{dS}$ values on branches leading to taxa with enamel-capped teeth (Table 3). Collectively, the results of selection analyses are consistent with the hypothesis that C4orf26 is tooth-specific, but not enamel-specific.

Given the occurrence of inactivating mutations in five edentulous taxa (Manis pentadactyla, Balaena mysticetus, Eubalaena australis, E. glacialis, Balaenoptera musculus), as well as the apparent deletion of this gene in seven balaenopteroid mysticetes (Eschrichtius robustus, Megaptera novaeangliae, Balaenoptera acutorostrata, B. bonaerensis, B. physalus, B. borealis, B. brydei), we surveyed all available genomes of placental mammals on Ensembl/NCBI, supplemented by our exon capture hybridization data for two species with enamel-capped teeth (Choeropsis liberiensis [pygmy hippopotamus], Delphinapterus leucas [beluga]), to provide a more extended test of the hypothesis that $C 4 \operatorname{orf} 26$ is tooth-specific and remains intact in all species with teeth that are capped by enamel. We note that many of these genomes are not annotated. Our final data set (Supplementary Alignment File 4) included complete coding sequences (exon 1 and exon 3) for 95 taxa with enamel-capped teeth, three taxa with enamelless teeth, and five edentulous taxa. A RAxML phylogram for C4orf 26 sequences is shown in Figure 3 and is consistent with the monophyly of Afrotheria, Xenarthra, Laurasiatheria, and Euarchontoglires. All sequences for taxa with enamel-capped teeth are putatively functional based on "ATG" start codons and intact protein-coding sequences that lack frameshift mutations and premature stop codons (Supplementary Alignment File 4). Also, all taxa with enamel-capped teeth have canonical "AG" and "GT" splice site sequences.

Blast searches further suggest that $C 4$ orf 26 is present (and intact) in marsupials (Sarcophilus harrisii [AFEY01438122]; Monodelphis domestica [AAFR03038381]), although we were unable to find this gene in the monotreme Ornithorhynchus anatinus (platypus) or in other amniotes. Thus, C4orf26 may be a neomorph of therian mammals.

A second transcript variant of C4orf26 (NM_001206981.1) includes an additional short exon (exon 2, 44 bp in Homo sapiens) and results in a protein that only shares the first 22 amino acid residues with the variant (NM_178497.3) that is encoded by exon1 + 
exon 3 (Parry et a. 2012). However, putative orthologs of this transcript in Homo have only been identified in Pan troglodytes (chimpanzee) and Nomascus leucogenys (northern white-cheeked gibbon) and it is unclear if this transcript plays any role in amelogenesis (Parry et al., 2012). We surveyed available placental mammal genomes to determine if there is genomic evidence for the presence of a functional copy of exon 2 (and potentially a second transcript) outside of Hominoidea (apes and humans).

Sequences for putative exon 2 are intact (canonical splice sites, intact coding sequence) in 16 catarrhine primates (Old World monkeys and apes), as well as in 18 other placental mammals that are scattered across Euarchontoglires (Callithrix [marmoset], Propithecus [sifaka], Tupaia [treeshrew], Oryctolagus [rabbit]), Laurasiatheria (Cetacea [toothed whales and bowhead], Equus [horses], Ursidae [bears], Canis [dog], three chiropterans [Eptesicus, Myotis lucifugus, Pteronotus]), and Xenarthra (Choloepus [sloth]), but a putatively functional copy of this exon is missing from 60 other placental mammals including all available afrotherians (seven taxa), one xenarthran (Dasypus [armadillo]), two platyrrhine primates, three strepsirrhine primates, Galeopterus (colugo), Ochotona (pika), Rodentia (16 taxa), non-cetacean cetartiodactyls (14 taxa), Ceratotherium (white rhinoceros), four carnivorans, Manis (pangolin), seven chiropterans, and Condylura (starnosed mole) based on various inactivating mutations. Moreover, the incorporation of an intact exon 2 into an alternative splice site variant requires translation of exon 3 in a different reading frame as well as a different stop codon. In all 16 catarrhine primates, exon 3 can be translated in this alternate reading frame without premature stop codons and there are suitable stop codons located downstream of the original stop codon. However, the incorporation of exon 2 into a putative transcript almost always results in a premature stop codon in other placental mammals where exon 2 is seemingly intact. In this alternative reading frame, premature stop codons are commonly encountered in the first third of exon 3, and in some cases within the first few codons (e.g., codon five in sloth). The only non-catarrhine placental mammal without a premature stop codon is Oryctolagus cuniculus, where exon 3 is five bp longer when read in the alternative reading frame.

\section{Discussion}


Vertebrate evolution has produced an impressive array of toothless and enamelless lineages, including numerous placental mammals that are either edentulous (pangolins, baleen whales, anteaters, Steller's sea cow) or enamelless (aardvark, sloths, armadillos, pygmy and dwarf sperm whales, narwhal). All of these forms have descended from ancestors with enamel-capped teeth, and may be employed to test hypotheses that individual genes are either tooth-specific or enamel-specific with respect to their essential functions that are maintained by natural selection. Enamel-specific genes should accumulate molecular cavities in edentulous and enamelless taxa, whereas genes that are tooth-specific (or dentin-specific), but not enamel-specific, should accumulate inactivating mutations in edentulous taxa but not in taxa with enamelless teeth. Previous studies have utilized gene sequences from one or more of the above-mentioned taxa, as well as toothless birds and turtles, to show that six genes (AMBN, AMEL, AMTN, ENAM, $K L K 4, M M P 20$ ) are enamel-specific with respect to their essential functions that are maintained by natural selection (Deméré et al., 2008; Meredith et al., 2009, 2011a, 2013, 2014; Gasse et al., 2012; Delsuc et al., 2015; Springer et al., 2015), whereas DSPP is dentin-specific and is only inactivated in edentulous vertebrates (McKnight and Fisher, 2009; Meredith et al., 2014). Here, we employed genomes sequences from two edentulous lineages (Chinese pangolin, baleen whales) and three lineages with enamelless teeth (aardvark, Hoffman's two-toed sloth, nine-banded armadillo) to test hypotheses of enamel-specificity for four different genes: C4orf26, FAM83H, SLC24A4, and WDR72. Our results suggest that FAM83H, SLC24A4, and WDR72 are pleiotropic and have essential roles outside of tooth or enamel formation, whereas C4orf26 is tooth specific.

Certain mutations in FAM83H are associated with autosomal-dominant hypocalcified AI (Kim et al., 2008; Lee et al., 2011; Urzúa et al., 2015; Zhang et al., 2015). By contrast, overexpression of FAM83H does not cause any dentine or enamel malformations (Kweon et al., 2013). Although AI caused by FAM83H mutations is not associated with other phenotypic defects, FAM83H is widely expressed in different tissues based on expressed sequence tags (Lee et al., 2011). Also, Forman et al. (2012) found a single bp frameshift deletion in FAM83H that results in congenital 
keratoconjunctivitis sicca and ichthyosiform dermatosis (CKCSID), commonly known as dry eye curly coat syndrome, in a domestic dog breed (Cavalier King Charles Spaniel). This phenotype suggests that FAM $83 H$ is important for proper skin development and regulation, in addition to proper enamel formation, at least in the domestic dog (Forman et al., 2012).

WDR72 is a putative beta propeller protein that may facilitate vesicle trafficking in maturation stage ameloblasts (El-Sayed et al., 2009; Wang et al., 2015). Certain mutations in WDR72 are associated with autosomal-recessive hypomaturation AI (ElSayed et al., 2009). However, in almost all cases the only observed phenotypic deficiency is in enamel formation (El-Sayed et al., 2009; Lee et al., 2010; Wright et al., 2011; Katsura et al., 2014). The only exception is a mutation where AI is presented with short stature (Kuechler et al., 2012). Genome-wide association studies have suggested a role for WDR72 in renal function (Köttgen et al., 2010; Okada et al., 2012; Franceschini et al., 2014) and neurocognitive function (LeBlanc et al., 2012). The retention of a functional copy of WDR72 in both enamelless and toothless mammals provides compelling evolutionary evidence that this gene is pleiotropic and performs essential functions outside of tooth development that are maintained by natural selection within Mammalia.

SLC24A4 is a potassium-dependent sodium-calcium ion exchanger (Wang et al., 2014). It is expressed in the maturation stage of amelogenesis where the protein localizes along the ameloblast distal membrane next to the mineral layer (Wang et al., 2014). Some mutations in SLC24A4 are known to cause autosomal-recessive hypomaturation AI in humans without other noticeable phenotypic defects (Parry et al., 2013; Seymen et al., 2014; Wang et al., 2014; Herzog et al., 2015). Nevertheless, SLC24A4 null mice have reduced olfactory capacity (Stephan et al., 2012) and SLC24A4 transcripts are also abundant in the brain, lungs, aorta, and thymus of mouse (Li et al., 2002). Genome-wide association studies in humans have also suggested a role for SLC24A4 in determining eye and hair color (Sulem et al., 2007; Larrson et al., 2011), blood pressure (Adeyemo et al., 2009), and cognitive function (Lambert et al., 2013). Given the numerous roles that have been suggested for $S L C 24 A 4$, it is not surprising that this gene remains intact in edentulous and enamelless mammals. 
In contrast to FAM83H, SLC24A2, and WDR72, C4orf26 is inactivated in edentulous species (pangolin and baleen whales). Inactivation of C4orf 26 in these forms, but not in placental mammals with teeth (enamel-capped or enamelless), suggests that C4orf26 is tooth-specific, but not enamel-specific, with respect to its essential functions that are maintained by natural selection. A caveat is that catarrhine primates have an alternative splice site variant that translates exon 3 in a different reading frame. The function of this putative splice site variant is unknown (Parry et al., 2012). Thus, C4orf26 may have an essential function in catarrhine primates that is unrelated to tooth development. Human C4orf 26 has been identified as a member of a prognostic gene set for lymph-node-negative breast cancer (Karlsson et al., 2008).

Meredith et al. (2014) provided evidence that five enamel-related genes ( $A M B N$, AMEL, AMTN, ENAM, MMP20) and one dentin-related gene (DSPP) are inactivated in Manis pentadactyla (Chinese pangolin), which is edentulous. The finding that C4orf26 is also inactivated in $M$. pentadactyla brings the total number of inactivated tooth-related genes to seven in this taxon. A dN/dS value of $\sim 1.95-2.00$ on the pangolin branch suggests that positive selection may have acted on C4orf26 prior to its inactivation, but statistical tests failed to reject the null hypothesis of neutral evolution $(\mathrm{dN} / \mathrm{dS}=1.0)$. Still, the $\mathrm{dN} / \mathrm{dS}$ value $>1.0$ on this branch implies that inactivation of $C 4$ orf 26 occurred very soon after pangolins diverged from their sister group, Carnivora, in the Late Cretaceous ( 79.2 Ma, Meredith et al., 2011b) or near the KPg boundary ( 65.5 Ma, dos Reis et al., 2012). The oldest fossil pangolin (Eomanis waldi) is from the Messel deposits in Germany, which have been dated at $47 \mathrm{Ma}$ (Franzen, 2005). Eomanis is edentulous, which is consistent with the hypothesis that tooth loss is very ancient in Pholidota. Other explanations for the high $\mathrm{dN} / \mathrm{dS}$ ratio in M. pentadactyla include alignment errors and/or model mis-specification in PAML that does not match the more complicated substitution process of the real world. Specifically, PAML assumes a single codon model for all sequences and does not allow for a heterogeneous codon frequency model wherein base composition and relative rates of substitution (e.g., $\mathrm{G}$ to $\mathrm{A}$ versus $\mathrm{G}$ to $\mathrm{C}$ ) differ between functional and pseudogenic sequences.

Previous studies have also documented inactivation of five enamel-specific genes (AMBN, AMEL, ENAM, KLK4, MMP20) in one or more baleen whales (Deméré et al., 
2008; Meredith et al., 2009, 2011a, 2014; Kawasaki et al., 2014). Of these, MMP20 exhibits a SINE insertion that is shared by all baleen whales. This shared mutation provides evidence that the genetic toolkit for making enamel was disrupted in the common ancestor of extant baleen whales (Meredith et al., 2011a), but inactivating mutations in additional enamel or tooth-specific genes in the common ancestor have not been documented. Recently described fossils show evidence of vestigial teeth in the jaws of adult eomystisticetids, close relatives of crown group mysticetes (Okazaki, 2012; Boessenecker and Fordyce, 2015a, b). This suggests the possibility that the last common ancestor of extant mysticetes also retained vestigial teeth in adults. Fetal tooth buds are present in extant mysticetes but these rudiments are resorbed before birth and are not expressed in adults (Deméré et al., 2008 and references therein).

Three baleen whales with genome sequences (two minke whales, bowhead whale) show evidence for inactivation or loss of C4orf26. These genomes, in combination with additional sequences obtained via PCR and Sanger sequencing, suggest that C4orf26 was not inactivated in the common ancestor of baleen whales and instead was inactivated independently in balaenids (Balaena, Eubalaena) based on a shared mutation in the start codon ("ATG" to "TTG") and also in Balaenopteroidea (rorquals and gray whale) based on the shared deletion of this gene in seven taxa that index the basal cladogenic split within this clade (Fig. 4). However, the deletion of C4orf26 that occurs in seven balaenopteroid species is not shared by Balaenoptera musculus (blue whale) that retains exons 1 and 3 in its genome. This pattern suggests incomplete lineage sorting of alternative alleles for this gene, with one allele presenting the ancestral presence of protein-coding exons and the other allele characterized by complete deletion of these exons. Similar patterns of incomplete lineage sorting in Balaenopteroidea have been suggested for SINE elements in Balaenopteroidea (Nikaido et al., 2006) as well as the enamel-specific gene ENAM (Deméré et al., 2008; Meredith et al., 2009). Importantly, the C4of 26 gene sequences for B. musculus do not share any inactivating substitutions with members of Balaenidae, which implies that C4orf26 was not inactivated in the common ancestor of extant baleen whales. Instead, B. musculus is characterized by unique inactivating substitutions that coincidentally occur at the same locations (start codon, donor splice site for intron 1) as the inactivating substitutions in Balaena 
mysticetus (Figs. 1, 4). Given evidence from the fossil record (Fitzgerald, 2006; Boessenecker and Fordyce, 2015a, b), documented patterns of shared inactivating mutations in different tooth-specific genes (Deméré et al., 2008; McKnight and Fisher, 2009; Meredith et al., 2009, 2011a), and ancestral reconstructions for tooth loss in Mysticeti (Meredith et al. 2011a), it remains unclear if teeth, rather than just enamel, were lost in the common ancestor of crown Mysticeti or independently in multiple mysticete lineages. The evolution of edentulism in the common ancestor of crown Mysticeti appears more likely, but in the absence of a shared, inactivating mutation for tooth loss we would not be surprised by future fossil discoveries that document vestigial teeth, albeit without enamel, in basal members of crown Mysticeti. However, it is also possible that edentulism in Mysticeti resulted from changes in the expression of one or more pleiotropic genes, in which case the accumulation of inactivating mutations in enamel and other tooth-specific genes may have lagged behind the evolutionary loss of teeth (Meredith et al., 2011a). This scenario is plausible for mysticetes given the extremely slow rate of molecular evolution in baleen whales (Meredith et al., 2011a).

In summary, vertebrate evolution can be viewed as an extensive natural laboratory, with replicated experiments in which enamel and the entire dentition have each been lost multiple times. Gene and genome sequences from this laboratory provide compelling phylogenetic evidence that eight different genes (AMBN, AMEL, AMTN, C4orf26, DSPP, ENAM, KLK4, MMP20) are either enamel-specific or tooth-specific with respect to their critical functions that are maintained by natural selection. In conjunction with reports of non-syndromic AI and DI in humans, genome-wide association studies, and knockout/knockin experiments in mice, geneticists are equipped with a multipronged approach for testing hypotheses of tooth and/or enamel specific gene function.

Acknowledgments. This work was supported by NSF grant DEB-1457735 to J.G., M.S.S., and P.A.M. We thank R. Boessenecker and R. Meredith for helpful comments. For providing DNA samples, we thank Southwest Fisheries Science Center-Genetics Archive (LaJolla, CA), the New York Zoological Society (Bronx, NY), South Australian Museum (Adelaide, Australia), the Marine Mammal Center (Sausalito, CA), North Slope Borough (Barrow, AK), Northeast Fisheries Science Center (Woods Hole, MA), G. 
Amato, P. Clapham, and H. Rosenbaum. We thank A. Aguilar for photos; other artwork was provided by C. Buell and R. Boessenecker.

\section{References}

Adeyemo, A., Gerry, N., Chen, G., Herbert, A., Doumatey, A., Huang, H., Zhou, J., Lashley, K., Chen, Y., Christman, M., Rotimi, C., 2009. A genome-wide association study of hypertension and blood pressure in African Americans. PLoS Genet. 5, e1000564.

Atsawasuwan, P., Lu, X., Ito, Y., Chen, Y., Gopinathan, G., Evans, C.A., Kulkarni, A.B., Gibson, C.W., Luan, X., Diekwisch, T.G.H., 2013. Expression and function of enamelrelated gene products in calvarial development. J. Dent. Res. 92, 622-628.

Boessenceker, R.W., Fordyce, R.E., 2015a. Anatomy, feeding ecology, and ontogeny of a transitional baleen whale: a new genus and species of Eomysticetidae (Mammalia: Cetacea) from the Oligocene of New Zealand. PeerJ 3, e1129.

Boessenceker, R.W., Fordyce, R.E., 2015b. A new genus and species of eomysticetid (Cetacea: Mysticeti) and a reinterpretation of "Mauicetus" lophocephalus Marples, 1956: transitional baleen whales from the upper Oligocene of New Zealand. Zool. J. Linn. Soc. doi: 10.1111/zoj.12297.

Caton, J., Tucker, A.S., 2009. Current knowledge of tooth development: patterning and mineralization of the murine dentition. J. Anat. 219, 502-515.

Chan, H.-C., Estrella, N.M.R.P., Milkovich, R.N., Kim, J.-W., Simmer, J.P., Hu, J.C.-C., 2011. Target gene analyses of 39 amelogenesis imperfecta kindreds. Eur. J. Oral Sci. 119 
(Suppl. 1), 311-323.

Davit-Béal, T., Tucker, A.S., Sire, J.-Y., 2009. Loss of teeth and enamel in tetrapods: fossil record, genetic data and morphological adaptations. J. Anat. 214, 477-501.

Delsuc, F., Gasse, B., Sire, J.-Y., 2015. Evolutionary analysis of selective constraints identifies ameloblastin $(A M B N)$ as a potential candidate for amelogenesis imperfecta. BMC Evol. Biol. 15, 148.

Deméré, T.A., McGowen, M.R., Berta, A., Gatesy, J., 2008. Morphological and molecular evidence for a stepwise evolutionary transition from teeth to baleen in mysticete whales. Syst. Biol. 57, 15-37.

Deutsch, D., Haze-Filderman, A., Blumenfeld, A., Dafni, L., Leiser, Y., Shay, B., Gruenbaum-Cohen, Y., Rosenfeld, E., Fermon, E., Zimmerman, B., Haegewald, S., Bernimoulin, J.-P., Taylor, A. L., 2006. Amelogenin, a major structural protein in mineralizing enamel, is also expressed in soft tissues: brain and cells of the hematopoietic system. Eur. J. Oral Sci. 114 (Suppl. 1), 183-189.

dos Reis, M., Inoue, J., Hasegawa, M., Asher, R.J., Donoghue, P.C.J., Yang, Z., 2012. Phylogenomic datasets provide both precision and accuracy in estimating the timescale of placental mammal phylogeny. Proc. R. Soc. B 279, 3491-3500.

Edgar, R.C., 2005. MUSCLE: a multiple sequence alignment method with reduced time and space complexity. BMC Bioinformatics 5, 113.

El-Sayed, W., Parry, D.A., Shore, R.C., Ahmed, M., Jafri, H., Rashid, Y., Al-Bahlani, S., Al Harasi, S., Kirkham, J., Inglehearn, C.F., Mighell, A.J., 2009. Mutations in the beta propeller WDR72 cause autosomal-recessive hypomaturation amelogenesis imperfecta. Am. J. Hum. Genet. 85, 699-705. 
Fitzgerald, E.M.G., 2006. A bizarre new toothed mysticete (Cetacea) from Australia and the early evolution of baleen whales. Proc. R. Soc. B 273, 2955-2963.

Franceschini, N., Haack, K., Almasy, L., Laston, S., Lee, E.T., Best, L.G., Fabsitz, R.R., MacCluer, J.W., Howard, B.V., Umans, J.G., Cole, S.A., 2014. Generalization of associations of kidney related genetic loci to American Indians. Clin. J. Am. Soc. Nephrol. 9, 150-158.

Franzen, J.L., 2005. The implications of the numerical dating of the Messel fossil deposit (Eocene, Germany) for mammalian biochronology. Annal. Paleontol. 91, 329-335.

Forman, O.P., Penderis, J., Hartley, C., Hayward, L.J., Ricketts, S.L., Mellersh, C.S., 2012. Parallel mapping and simultaneous sequencing reveals deletions in BCAN and FAM83H assocated with discrete inherited disorders in a domestic dog breed. PLoS Genet. 8, e1002462

Fuchs, H., Sabrautzki, S., Seedorf, H., Rathkolb, B., Rozman, J., Hans, W., Schneider, R., Klaften, M., Hölter, S.M., Becker, L., Klempt, M., Elvert, R., Wurst, W., Klopstock, T., Klingenspor, M., Wolf, E., Gailus-Durner, V., Hrabě de Angelis, M., 2012. Does enamelin have pleiotropic effects on organs other than the teeth? Lessons from a phenotyping screen of two enamelin-mutant mouse lines. Eur. J. Oral Sci. 120, 269-77.

Fukumoto, S., Kiba, T., Hall, B., Iehara, N., Nakamura, T., Longenecker, G., Krebsbach, P.H., Nanci, A., Kulkarni, A.B., Yamada, Y., 2004. Ameloblastin is a cell adhesion molecule required for maintaining the differentiation state of ameloblasts. J. Cell Biol. $167,973-983$.

Gaetano, J., 2013. Holm-Bonferroni sequential correction: An EXCEL calculator (1.1) [Microsoft Excel workbook]. doi:10.13140/RG.2.1.4466.9927 
Gasse, B., Silvent, J., Sire, J.-Y., 2012. Evolutionary analysis suggests that AMTN is enamel-specific and a candidate for AI. J. Dent. Res. 91, 1085-1089.

Gibson, C.W., Yuan, Z.-A., Hall, B., Longenecker, G., Chen, E., Thyagarajan, T., Sreenath, T., Wright, J.T., Decker, S., Piddington, R., Harrison, G., Kulkarni, A.B., 2001. Amelogenin-deficient mice display an amelogenesis imperfecta phenotype. J. Biol. Chem. 276, 31871-31875.

Greenlee, K. J., Werb, Z., Kheradmand, F., 2007. Matrix metalloproteinases in lung: multiple, multifarious, and multifaceted. Physiol. Rev. 87, 69-98.

Hart, P. S., Hart, T. C., Michalec, M. D., Ryu, O. H., Simmons, D., Hong, S., Wright, J. T., 2004. Mutation in kallikrein 4 causes autosomal recessive hypomaturation amelogenesis imperfecta. J. Med. Genet. 41, 545-549.

Haze, A., Taylor, A.L., Blumenfeld, A., Rosenfeld, E., Leiser, Y., Dafni, L., Shay, B., Gruenbaum-Cohen, Y., Fermon, E., Haegewald, S., Bernimoulin, J.-P., Deutsch, D., 2007. Amelogenin expression in long bone and cartilage cells and in bone marrow progenitor cells. Anat. Rec. 290, 455-460.

Herzog, C.R., Reid, B.M., Seymen, F., Koruyucu, M., Tuna, E.B., Simmer, J.P., Hu, J.C.C., 2015. Hypomaturation amelogenesis imperfecta caused by a novel SLC24A4 mutation. Oral Maxillofacial Pathol. 119, e77-e81.

Holm, S., 1979. A simple sequentially rejective multiple test procedure. Scandinavian J. Stat. 6, 65-70.

Katoh, K., Misawa, K., Kuma, K., Miyata, T., 2002. MAFFT: a novel method for rapid multiple sequence alignment based on fast Fourier transform. Nuc. Acids Res. 30, 30593066. 
Karlsson, E., Delle, U., Danielsson, A., Olsson, B., Abel, F., Karlsson, P., Helou, K., 2008. Gene expression variation to predict 10-year survival in lymph-node-negative breast cancer. BMC Cancer 8, 254.

Katsura, K.A., Horst, J.A., Chandra, D., Le, T.Q., Nakano, Y., Zhang, Y., Horst, O.V., Zhu, L., Le, M.H., DenBesten, P.K., 2014. WDR72 models of structure and function: a stage-specific regulator of enamel mineralization. Matrix Biol. 38, 48-58.

Kawasaki, K., Hu, J.C.-C., Simmer, J.P., 2014. Evolution of Klk4 and enamel maturation in eutherians. Biol. Chem. 395, 1003-1013.

Keane, M., Semeiks, J., Webb, A.E., Li, Y.I., Quesada, V., Craig, T., Madsen, L.B., van Dam, S., Brawand, D., Marques, P.I., Michalak, P., Kang, L., Bhak, J., Yim, Y.-S., Grishin, N.V., Hielsen, N.H., Heide-Jørgensen, Oziolor, E.M., Matson, C.W., Church, G.M., Stuart, G.W., Patton, J.C., George, J.C., Suydam, R., Larsen, K., López-Otín, C., O’Connell, J.O., Bickham, J.W., thomsen, B., de Magalhães, J.P., 2015. Insights into the evolution of longevity from the bowhead whale genome. Cell Reports 10, 112-122.

Kearse, M., Moir, R., Wilson, A., Stones-Havas, S., Cheung, M., Sturrock, S., Buxton, S., Cooper, A., Markowitz, S., Duran, C., Thierer, T., Ashton, B., Mentjies, P., Drummond, A., 2012. Geneious Basic: an integrated and extendable desktop software platform for the organization and analysis of sequence data. Bioinformatics 28, 1647-1649.

Kim, J.W., Lee, S.K., Lee, Z.H., Park, J.C., Lee, K.E., Lee, M.H., Park, J.T., Seo, B.M., Hu, J.C., Simmer, J.P., 2008. FAM83H mutations in families with autosomal-dominant hypocalcified amelogenesis imperfecta. Am. J. Hum. Genet. 82, 489-494.

Köttgen, A., Pattaro, C., Böger, C.A., Fuchsberger, C., Olden, M., Glazer, N.L., Parsa, A., Gao, X., Yang, Q., Smith, A.V., O'Connell, J.R., Li, M., Schmidt, H., Tanaka, T., Isaacs, A., Ketkar, S., Hwang, S.J., Johnson, A.D., Dehghan, A., Teumer, A., Paré, G., Atkinson, E.J., Zeller, T., Lohman, K., Cornelis, M.C., Probst-Hensch, N.M., 
Kronenberg, F., Tönjes, A., Hayward, C., Aspelund, T., Eiriksdottir, G., Launer, L.J., Harris, T.B., Rampersaud, E., Mitchell, B.D., Arking, D.E., Boerwinkle, E., Struchalin, M., Cavalieri, M., Singleton, A., Giallauria, F., Metter, J., de Boer, I.H., Haritunians, T., Lumley, T., Siscovick, D., Psaty, B.M., Zillikens, M.C., Oostra, B.A., Feitosa, M., Province, M., de Andrade, M., Turner, S.T., Schillert, A., Ziegler, A., Wild, P.S., Schnabel, R.B., Wilde, S., Munzel, T.F., Leak, T.S., Illig, T., Klopp, N., Meisinger, C., Wichmann, H.E., Koenig, W., Zgaga, L., Zemunik, T., Kolcic, I., Minelli, C., Hu, F.B., Johansson, Å., Igl, W., Zaboli, G., Wild, S.H., Wright, A.F., Campbell, H., Ellinghaus, D., Schreiber, S., Aulchenko, Y.S., Felix, J.F., Rivadeneira, F., Uitterlinden, A.G., Hofman, A., Imboden, M., Nitsch, D., Brandstatter, A., Kollerits, B., Kedenko, L., Magi, R., Stumvoll, M., Kovacs, P., Boban, M., Campbell, S., Endlich, K., Volzke, H., Kroemer, H.K., Nauck, M., Volker, U., Polasek, O., Vitart, V., Badola, S., Parker, A.N., Ridker, P.M., Kardia, S.L., Blankenberg, S., Liu, Y., Curhan, G.C., Franke, A., Rochat, T., Paulweber, B., Prokopenko, I., Wang, W., Gudnason, V., Shuldiner, A.R., Coresh, J., Schmidt, R., Ferrucci, L., Shlipak, M.G., van Duijn, C.M., Borecki, I., Kramer, B.K., Rudan, I., Gyllensten, U., Wilson, J.F., Witteman, J.C., Pramstaller, P.P., Rettig, R., Hastie, N., Chasman, D.I., Kao,W.H., Heid, I.M., Fox, C.S., 2010. New loci associated with kidney function and chronic kidney disease. Nat. Genet. 42, 376-384.

Kuechler, A., Hentschel, J., Kurth, I., Stephan, B., Prott, E.C., Schweiger, B., Schuster, A., Wieczorek, D., Ludecke, H.J., 2012. A novel homozygous WDR72 mutation in two siblings with amelogenesis imperfecta and mild short stature. Mol. Syndromol. 3, 223229.

Kweon, Y.-S., Lee, K.-E., Ko, J., Hu, J. C.-C., Simmer, J.P., Kim, J.-W., 2013. Effects of Fam83h overexpression on enamel and dentine formation. Arch. Oral Biol. 58, 11481154.

Lambert, J.-C., Ibrahim-Verbaas, C.A., Harold, D., Naj, A.C., Sims, R., Bellenguez, C., Jun, G., DeStefano, A.L., Bis, J.C., Beecham, G.W., et al., 2013. Meta-analysis of 74,046 
individuals identifies 11 new susceptibility loci for Alzheimer's disease. Nat. Genet. 45, 1452-1458.

Larrson, M., Duffy, D.L., Zhu, G., Liu, J.Z., Macgregor, S., McRae, A.F., Wright, M.J., Sturm, R.A., Mackey, D.A, Montgomery, G.W., Martin, N., Medland, S.E., 2011. GWAS findings for human iris patterns: associations with variants in genes that influence normal neuronal pattern development. Am. J. Hum. Genet. 89, 334-343.

LeBlanc, M., Kulle, B., Sundet, K., Agartz, I., Melle, I., Djurovic, S., Frigessi, A., Andreassen, O.A, 2012. Genome-wide study identifies PTPRO and WDR72 and FOXQ1SUMO1P1 interaction associated with neurocognitive function. J. Psychiatric Res. 46, 271-278.

Lee, S.K., Seymen, F., Lee, K.E., Kang, H.Y., Yildirim, M., Tuna, E.B., Gencay, K., Hwang, Y.H., Nam, K.H., De La Garza, R.J., Hu, J.C., Simmer, J.P., Kim, J.W., 2010. Novel WDR72 mutation and cytoplasmic localization. J. Dent. Res. 89, 1378-1382.

Lee, S.-K., Lee, K.-E., Jeong, T.-S., Hwang, Y.-H., Kim, S., Hu, J.C.-C., Simmer, J.P., Kim, J.-W., 2011. FAM83H mutations cause ADHCAI and alter intracellular protein localization. J. Dent. Res. 90, 377-381.

Li, X.F., Kraev, A.S., Lytton, J., 2002. Molecular cloning of a fourth member of the potassium-dependent sodium-calcium exchanger gene family, NCKX4. J Biol Chem. 277, $48410-48417$.

Maddison, W.P., 1997. Gene trees in species trees. Syst. Biol. 46, 523-536.

Marx, F.G., Fordyce, R.E., 2015. Baleen boom and bust: a synthesis of mysticete phylogeny, diversity, and disparity. R. Soc. Open Sci. 2, 140434. 
Madsen, O., Scally, M., Douady, C.J., Kao, D.J., DeBry, R.W., Adkins, R., Amrine, H.M., Stanhope, M.J., de Jong, W.W., Springer, M.S. 2001 Parallel adaptive radiations in two major clades of placental mammals. Nature 409, 610-614.

McGowen, M.R., Spaulding, M., Gatesy, J., 2009. Divergence date estimation and a comprehensive molecular tree of extant cetaceans. Mol. Phylogenet. Evol. 53, 891-906.

McKnight, D.A., Fisher, L.W., 2009. Molecular evolution of dentin phosphoprotein among toothed and toothless animals. BMC Evol. Biol. 9, 299.

Meredith, R., Gatesy, J., Murphy, W.J., Ryder, O.A., Springer, M.S., 2009. Molecular decay of the tooth gene enamelin (ENAM) mirrors the loss of enamel in the fossil record of placental mammals. PLoS Genet. 5, 1-12.

Meredith, R.W., Gatesy, J., Cheng, J., Springer, M.S., 2011a. Pseudogenization of the tooth gene enamelysin (MMP20) in the common ancestor of extant baleen whales. Proc. R. Soc. B 278, 993-1002.

Meredith, R.W., Janecka, J.E., Gatesy, J., Ryder, O.A., Fisher, C.A., Teeling, E.C., Goodbla, A., Eizirik, E., Simão, T.L.L., Stadler, T., Rabosky, D.L., Honeycutt, R.L., Flynn, J.J., Ingram, C.M., Steiner, C., Williams, T.L., Robinson, T.J., Burk-Herrick, A., Westerman, M., Ayoub, N.A., Springer, M.S., Murphy, W.J., 2011b. Impacts of the Cretaceous terrestrial revolution and KPg extinction on mammal diversification. Science $334,521-524$.

Meredith, R.W., Gatesy, J., Springer, M.S., 2013. Molecular decay of enamel matrix protein genes in turtles and other edentulous amniotes. BMC Evol. Biol. 13, 20.

Meredith, R.W., Zhang, G., Gilbert, M.T.P., Jarvis, E.D., Springer, M.S. 2014. Evidence for a single loss of mineralized teeth in the common avian ancestor. Science 346, 1254390. 
Miller, M.A., Pfeiffer, W., Schwartz, T., 2010. Creating the CIPRES Science Gateway for inference of large phylogenetic trees. Gateway Computing Environments Workshop, $1-8$.

Murphy, W.J., Eizirik, E., Johnson, W.E., Zhang, Y.P., Ryder, O.A., O’Brien, S.J., 2001a. Molecular phylogenetics and the origins of placental mammals. Nature 409, 614-618.

Murphy, W.J., Eizirik, E., O’Brien, S.J., Madsen, O., Scally, M., Douady, C.J., Teeling, E., Ryder, O.A., Stanhope, M.J., de Jong, W.W., Springer, M.S., 2001b. Resolution of the early placental mammal radiation using Bayesian phylogenetics. Science 294, 2348-2351.

Nikaido, M., Hamilton, H., Makino, H., Sasaki, T., Takahashi, K., Goto, M., Kanda, N., Pastene, L.A., Okada, N., 2006. Baleen whale phylogeny and a post extensive radiation event revealed by SINE insertion analysis. Mol. Biol. Evol. 23, 866-873.

Ogbureke, K.U.E., Fisher, L.W., 2004. Expression of SIBLINGs and their partner MMPs in salivary glands. J. Dent. Res. 83, 664-670.

Ogbureke, K.U., Fisher, L.W., 2005. Renal expression of SIBLING proteins and their partner matrix metalloproteinases (MMPs). Kidney Int. 68, 155-166.

Ogbureke, K.U., Fisher, L.W., 2007. SIBLING expression patterns in duct epithelia reflect the degree of metabolic activity. J. Histochem. Cytochem. 55, 403-409.

Okada, Y., Sim, X., Go, M.J., Wu, J.-Y., Gu, D., Takeuchi, F., Takahashi, A., Maeda, S., Tsunoda, T., Chen, P., Lim, S.-C., Wong, T.-Y., Liu, J., Young, T.L., Aung, T., Seielstad, M., Teo, Y.-Y., Kim, Y.J., Lee, J.-Y., Han, B.-G., Kang, D., Chen, C.-H., Tsai, F.-J., Chang, L.C., Fann, S.-J.C., Mei, H., Rao, D.C., Hixson, J.E., Chen, S., Katsuya, T., Isono, M., Ogihara, T., Chambers, J.C., Zhang, W., Kooner, J.S., The KidneyGen Consortium, The CKDGen Consortium, Albrecht, E., The GUGC consortium, 
Yamamoto, K., Kubo, M., Nakamura, Y., Kamatani, N., Kato, N., He, J., Chen, Y.-T., Cho, Y.S., Tai, E.-S., Tanaka, T., 2012. Meta-analysis identifies multiple loci associated with kidney function-related traits in east Asian populations. Nat. Genet. 44, 904-909.

Okazaki, Y., 2012. A new mysticete from the upper Oligocene Ashiya Group, Kyushu, Japan, and its significance to mysticete evolution. Bull. Kitakyushu Mus. Nat. Hist. Hu. Hist. Ser. A (Natural History) 10, 129-152.

Parry, D.A., Brookes, S.J., Logan, C.V., Poulter, J.A., El-Sayed, W., Al-Bahlani, S., Al Harasi, S., Sayed, J., Raif, E.M., Shore, R.C., Dashash, M., Barron, M., Morgan, J.E., Carr, I.M., Taylor, G.R., Johnson, C.A., Aldred, M.J., Dixon, M.J., Wright, J.T., Kirkham, J., Inglehearn, C.F., Mighell, A. J., 2012. Mutations in C4orf26, encoding a peptide with in vitro hydroxyapatite crystal nucleation and growth activity, cause amelogenesis imperfecta. Am. J. Hum. Gen. 91, 565-571.

Parry, D.A., Poulter, J.A., Logan, C.V., Brookes, S.J., Jafri, H., Ferguson, C.H., Anwari, B.M., Rashid, Y., Zhao, H., Johnson, C.A., Inglehearn, C.F., Mighell, A.J., 2013. Identification of mutations in SLC24A4, encoding a potassium-dependent sodium/calcium exchanger, as a cause of amelogenesis imperfecta. Am. J. Hum. Genet. 92, 307-312.

Qin, C., Brunn, J.C., Cadena, E., Ridall, A., Tsujigiwa, H., Nagatsuka, H., Nagai, N., Butler, W.T., 2002. The expression of dentin sialophosphoprotein gene in bone. J. Dent. Res. 81, 392-394.

Qin, C., Brunn, J.C., Cadena, E., Ridall, A., Butler, W.T., 2003. Dentin sialoprotein in bone and dentin sialophosphoprotein gene expressed by osteoblasts. Connective Tissue Res. 44 (Suppl. 1), 179-183.

Ryu, J., Vicencio, A.G., Yeager, M.E., Kashgarian, M., Haddad, G.G., Eickelberg, O., 2005. Differential expression of matrix metalloproteinases and their inhibitors in human 
and mouse lung development. Thromb. Haemostasis 94, 175-183.

Scally, M., Madsen, O., Douady, C.J., de Jong, W.W., Stanhope, M.J., Springer, M.S., 2001. Molecular evidence for the major clades of placental mammals. J. Mamm. Evol. 8, 239-277.

Schmieder, R., Edwards, R., 2011. Quality control and preprocessing of metagenomic datasets. Bioinformatics 27, 863-864.

Seiz, L., Kotzsch, M., Grebenchtchikov, N.I., Geurts-Moespot, A.J., Fuessel, S., Goettig, P., Gkazepis, A., Wirth, M.P., Schmitt, M., Lossnitzer, A., Sweep, F.C., Magdolen, V., 2010. Polyclonal antibodies against kallikrein-related peptidase 4 (KLK4):

immunohistochemical assessment of $K L K 4$ expression in healthy tissues and prostate cancer. Biol. Chem. 391, 391-401.

Seymen, F., Lee, K.-E., Tran Le, C.G., Yildirim, M., Gencay, K., Lee, Z.H., Kim, J.-W., 2014. Exonal deletion of SLC24A4 causes hypomaturation amelogenesis imperfecta. J. Dent. Res. 93, 366-370.

Shimamura, M., Yasue, H., Ohshima, K., Abe, H., Kato, H., Kishiro, T., Goto, M., Munechika, I., Okada, N., 1997. Molecular evidence from retroposons that whales form a clade within even-toed ungulates. Nature 388, 666-670.

Simmer, J.P., Hu, Y., Lertlam, R., Yamakoshi, Y., and Hu, J.C., 2009. Hypomaturation enamel defects in Klk4 knockout/LacZ knockin mice. J. Biol. Chem. 284, 19110-19121.

Smith, C.E., Wazen, R., Hu, Y., Zalzal, S.F., Nanci, A., Simmer, J.P., Hu, J. C.-C., 2009. Consequences for enamel development and mineralization resulting from loss of function of ameloblastin or enamelin. Eur. J. Oral Sci. 117, 485-497. 
Springer, M.S., Signore, A.V., Paijmans, J.L.A., Vélez-Juarbe, J., Domning, D.P., Bauer, C.E., He, K., Crerar, L., Campos, P.F., Murphy, W.J., Meredith, R.W., Gatesy, J., Willerslev, E., MacPhee, R.D.E., Hofreiter, M., Campbell, K.L., 2015. Interordinal gene capture, the phylogenetic position of Steller's sea cow based on molecular and morphological data, and the macroevolutionary history of Sirenia. Mol. Phylogenet. Evol. 91, 178-193.

Stamatakis, A., 2006. RAxML-VI-HPC: Maximum likelihood-based phylogenetic analyses with thousands of taxa and mixed models. Bioinformatics 22, 2688-2690.

Stamatakis, A., Hoover, P., Rougemont, J., 2008. A rapid bootstrap algorithm for the RAxML web servers. Syst. Biol. 57, 758-771.

Stephan, A.B., Tobochnik, S., Dibattista, M., Wall, C.M., Reisert, J., Zhao, H., 2012. The $\mathrm{Na}^{+} / \mathrm{Ca}^{2+}$ exchanger NCKX4 governs termination and adaptation of the mammalian olfactory response. Nat. Neurosci. 15, 131-137.

Steeman, M.E., Hebsgaard, M.B., Fordyce, R.E., Ho, S.Y.W., Rabosky, D.L., Nielsen, R., Rahbek, C., Glenner, H., Sørensen, M.V., Willerslev, E., 2009. Radiation of extant cetaceans driven by restructuring of the oceans. Syst. Biol. 58, 573-585.

Sulem, P., Gudbjartsson, D.F., Stacey, S.N., Helgason, A., Rafnar, T., Magnusson, K.P., Manolescu, A., Karason, A., Palsson, A., Thorleifsson, G., Jakobsdottir, M., Steinberg, S., Pálsson, S., Jonasson, F., Sigurgeirsson, B., Thorisdottir, K., Ragnarsson, R., Benediksdottir, K.R., Aben, K.K., Kiemeney, L.A., Olafsson, J.H., Gulcher, J., Kong, A., Thorsteinsdottir, U., Stafansson, K., 2007. Genetic detrminants of hair, eye and skin pigmentation in Europeans. Nat. Genet. 39, 1443-1452.

Turk, B.E., Lee, D.H., Yamakoshi, Y., Klingenhoff, A., Reichenberger, E., Wright, J.T., Simmer, J.P., Komisarof, J.A., Cantley, L.C., Bartlett, J. D., 2006. MMP-20 is predominately a tooth-specific enzyme with a deep catalytic pocket that hydrolyzes type 
V collagen. Biochemistry 45, 3863-3874.

Urzúa, B., Martinez, C., Ortega-Pinto, A., Adorno, D., 2015. Novel missense mutation of the FAM83H gene causes retention of amelogenin and a mild phenotype of hypocalcified enamel. Arch. Oral Biol. 60, 1356-1367.

Wang, S.K., Hu, Y., Simmer, J.P., Seymen, F., Estrella, N.M., Pal, S., Reid, B.M., Yildirim, M., Bayram, M., Bartlett, J.D., Hu, J.C.-C., 2013. Novel KLK4 and MMP2O mutations discovered by whole-exome sequencing. J. Dent. Res. 92, 266-271.

Wang, S., Choi, M., Richardson, A.S., Reid, B.M., Seymen, F., Yildirim, M., Tuna, E., Gençay, Simmer, J.P., Hu, J.C., 2014. STIM1 and SLC24A4 are critical for enamel maturation. J. Dent. Res. 93 (Suppl), 94S-100S.

Wheeler, H.E., Metter, E.J., Tanaka, T., Absher, D., Higgins, J., Zahn, J.M., Wilhelmy, J., Davis, R.W., Singleton, A., Myers, R.M., Ferrucci, L., Kim, S.K., 2009. Sequential use of transcriptional profiling, expression quantitative trait mapping, and gene association implicates MMP20 in human kidney aging. PLoS Genet. 5, e1000685.

Wright, J.T., Torain, M., Long, K., Seow, K., Crawford, P., Aldred, M.J., Hart, P.S., Hart, T.C., 2011. Amelogenesis imperfecta: genotype-phenotype studies in 71 families. Cells tissues Organs 194, 279-283.

Yang, Z., 2007. PAML 4: phylogenetic analysis by maximum likelihood. Mol. Biol. Evol. 24, 1586-1591.

Zhang, C., Song, Y., Bian, Z., 2015. Ultrastructural analysis of the teeth affected by amelogenesis imperfecta resulting from FAM83H mutations and review of the literature. Oral Maxillofacial Pathol. 119, e69-e76.

\section{Legends for Figures}


Fig. 1. Alignment of exon 1 (boxed) and flanking regions of C4orf26 for seven taxa. Manis pentadactyla (Chinese pangolin), Balaena mysticetus (bowhead whale), Eubalaena spp. (right whales), and Balaenoptera musculus (blue whale) are edentulous whereas Odobenus rosmarus (walrus) and Orcinus orca (killer whale) have enamel capped teeth. Inactivating mutations in $M$. pentadactyla are highlighted in pink and include a deletion that spans the start codon, a frameshift mutation within exon 1, and a deletion that includes the donor splice site for intron 1. Inactivating mutations in baleen whales are highlighted in blue and include mutated start codons ("TTG" in Balaena and Eubalaena; "ACG" in Balaenoptera) and donor splice site mutations ("GT" to "GG" in Balaena; "GT" to "AT" in Balaenoptera). Additional frameshift mutations in exon 3 of M. pentadactyla are shown in Supplementary Alignment File 4.

Fig. 2. Schematic alignment of contigs for Balaena mysticetus (scaffold 571), Balaenoptera acutorostrata (ATDI01091756), and Orcinus orca (ANOL02055947) that spans coding exons 1 and 3 of C4orf26. Exons 1 and 3 in B. mysticetus and O. orca are labeled with red triangles. CHR-2 SINE elements and their directionality (forward or reverse) are denoted with blue triangles. Both exons have been deleted from the genome of $B$. acutorostrata. The shaded pink box indicates the presence of a CHR-2 SINE element (Shimamura et al., 1997) in all three species. Asterisks above the $B$. acutorostrata sequence indicate the approximate position of primers that were used to amplify and screen other mysticete species for the presence of the B. acutorostrata deletion. The full alignment is available as Supplementary Alignment File 5.

Fig. 3. Maximum likelihood phylogram (-ln likelihood $=-10768.886570)$ for an alignment of 103 C4orf26 sequences (alignment length $=381 \mathrm{bp}$ ). Taxa with enamelless teeth are highlighted in green boxes. Enamel loss is hypothesized to have occurred independently in the two xenarthrans, C. hoffmani and D. novemcinctus as well as in Orycteropus (Meredith et al. 2009). Edentulous taxa are highlighted in pink boxes, with independent losses of teeth in Manis and in the common ancestor of mysticete whales. The superordinal clades Afrotheria, Xenarthra, Laurasiatheria, and Euarchontoglires are 
labeled on their respective stem braches. The tree was rooted between Afrotheria + Xenarthra and Laurasiatheria + Euarchontoglires. Ordinal names are in upper case. Scale bar is in substitutions per site. Paintings by Carl Buell.

Fig. 4. Evolution of the dentition and inactivating mutations in C4orf26 mapped onto a phylogenetic hypothesis for Mysticeti. Thick yellow branches show relationships and approximate ages of divergences among taxa. For crown mysticetes, the tree follows Steeman et al. (2009), and extinct taxa are positioned as in Boessenecker and Fordyce (2015a). Like the fin whale, Balaenoptera physalus (A, B), all extant mysticetes are toothless as adults and filter-feed using baleen (A); fetal stages express rudimentary teeth that are resorbed before birth (B). This condition is indicated by white circles in the tree. Recently described fossils that preserve shallow alveoli (tooth sockets) suggest that multiple eomysticetid species had vestigial teeth, as in the reconstruction of Waharoa ruwhenиa $(\mathrm{C})$, and simultaneously expressed baleen based on palatal anatomy (Okazaki, 2012; Boessenecker and Fordyce, 2015a, b). Eomysticetids generally have been coded as lacking teeth in previous phylogenetic studies (e.g., Fitzgerald, 2006, Deméré et al., 2008; Meredith et al., 2011a), because preservation of fossils in early descriptions did not permit detection of the shallow alveoli observed in recently described specimens (Boessenecker, pers. com.). By contrast, several species in the extinct clade Aetiocetidae have relatively robust, presumably functional dentitions in combination with small nutrient foramina and grooves on the palate that imply the presence of a baleen filter medial to the upper teeth, as in the reconstruction of Aetiocetus weltoni (D). Gray circles in the tree indicate the inferred, simultaneous presence of teeth and baleen in adults. Early mysticetes in the clade Mammalodontidae, such as Janjucetus hunderi (Fitzgerald, 2006), were toothed but lack osteological correlates for the presence of baleen, as is the case for crown odontocetes (toothed whales, dolphins, and porpoises). This condition is represented by black circles in the tree. The three states for teeth + baleen are mapped onto the tree by parsimony and suggest that the last common ancestor of extant mysticetes used baleen to filter-feed, lacked teeth in adults, but retained rudimentary fetal teeth. Inactivating mutations (black triangles) in the C4orf26 gene are mapped onto the same species tree (deltran optimization), assuming that incongruence between the gene 
tree (green and red lineages) and the species tree (yellow) is due to deep coalescence (Maddison, 1997), not to gene flow/introgression following divergence. See Results for description of mutations and their distributions among species; the reconstruction shown here suggests deletion of the C4orf 26 gene in the common ancestor of Balaenopteroidea (Eschrichtius, Megaptera, Balaenoptera = 'Bal.') with retention of ancestral polymorphism (presence versus absence of the gene) across subsequent speciation events. No shared inactivating mutations map to the common ancestor of extant mysticetes. Based on deltran optimization of inactivating mutations, functional (green) and pseudogenic (red) gene lineages are indicated. Alternative equally parsimonious optimizations map inactivating mutations in blue whale (Bal. musculus) to more basal internodes in the tree, and imply earlier inactivation of this allelic lineage. Eubalaena glacialis, a close relative of E. australis, is not shown to save space. The tree is scaled to the timeline at the bottom of the figure that is in millions of years (Plio-Pleist. = PlioPleistocene). Wholly extinct branches are represented by dotted lines with approximate ranges of extinct families shown as gray bars (based on Marx and Fordyce, 2015). Photos of fin whales are by A. Aguilar. Waharoa sketch is by R. Boessenecker, and remaining artwork is by C. Buell.

\section{Glossary}

Amelogenesis imperfecta: a group of inherited disorders that are characterized by abnormal enamel formation.

CHR-SINE: a group of short interspersed nuclear elements (SINEs) that are found in the genomes of Cetacea (C), Hippopotamidae (H), and Ruminantia (R). 
Manis pentadactyla Odobenus rosmarus Balaena mysticetus Eubalaena australis Eubalaena glacialis Balaenoptera musculus Orcinus orca

Manis pentadactyla Odobenus rosmarus Balaena mysticetus Eubalaena australis Eubalaena glacialis Balaenoptera musculus Orcinus orca
1

10

30 40 50

60 G T TGG T T TAAG G CAG - - - - - - - - - - - - - - - -

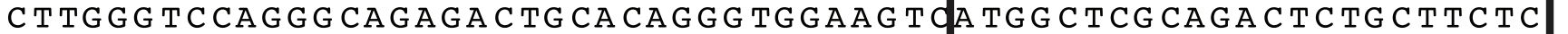
G TTGGG T TCAAGG CAG TGACTGCTTGGGG TAGAAG COTTGG TCACAGACTCTGCTTCTC

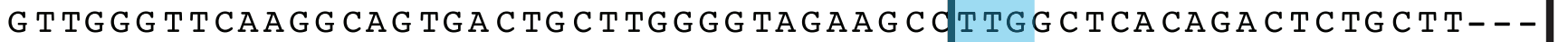

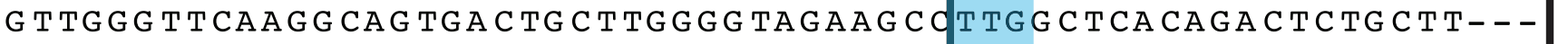

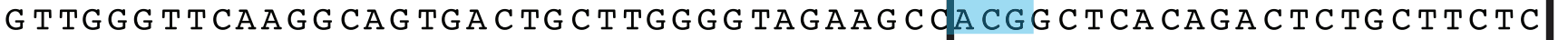

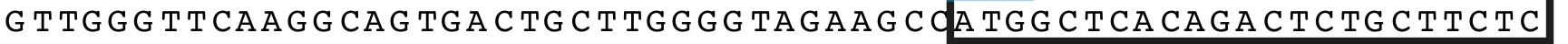
70 100 110

120 - - - - - - - - TG T T TG C-- - TG T TG G A A TG TG G CA - - - - - G A G G T T T T T T T С TA CTGG CTG TTGG TCTGCTGGG TGG TGG TAACTG TGG CA A A G TA A G T T T T T T T

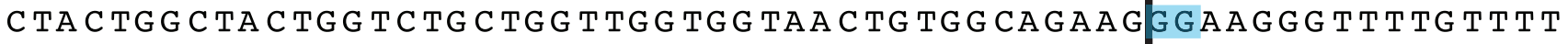

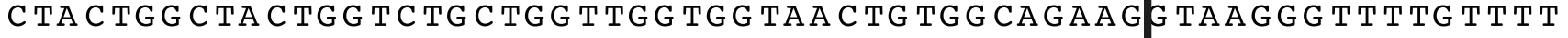

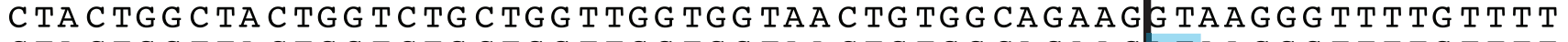

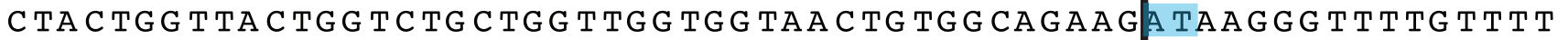
CTACTGG CTACTGG TCTGCTG TTG TG TAACTG TG CA AA G TA A G T T T T T T T 
Balaena mysticetus

Balaenoptera acutorostrata

Orcinus orca T

$>$

\section{Exon 1}

Exon 3 
Figure 3

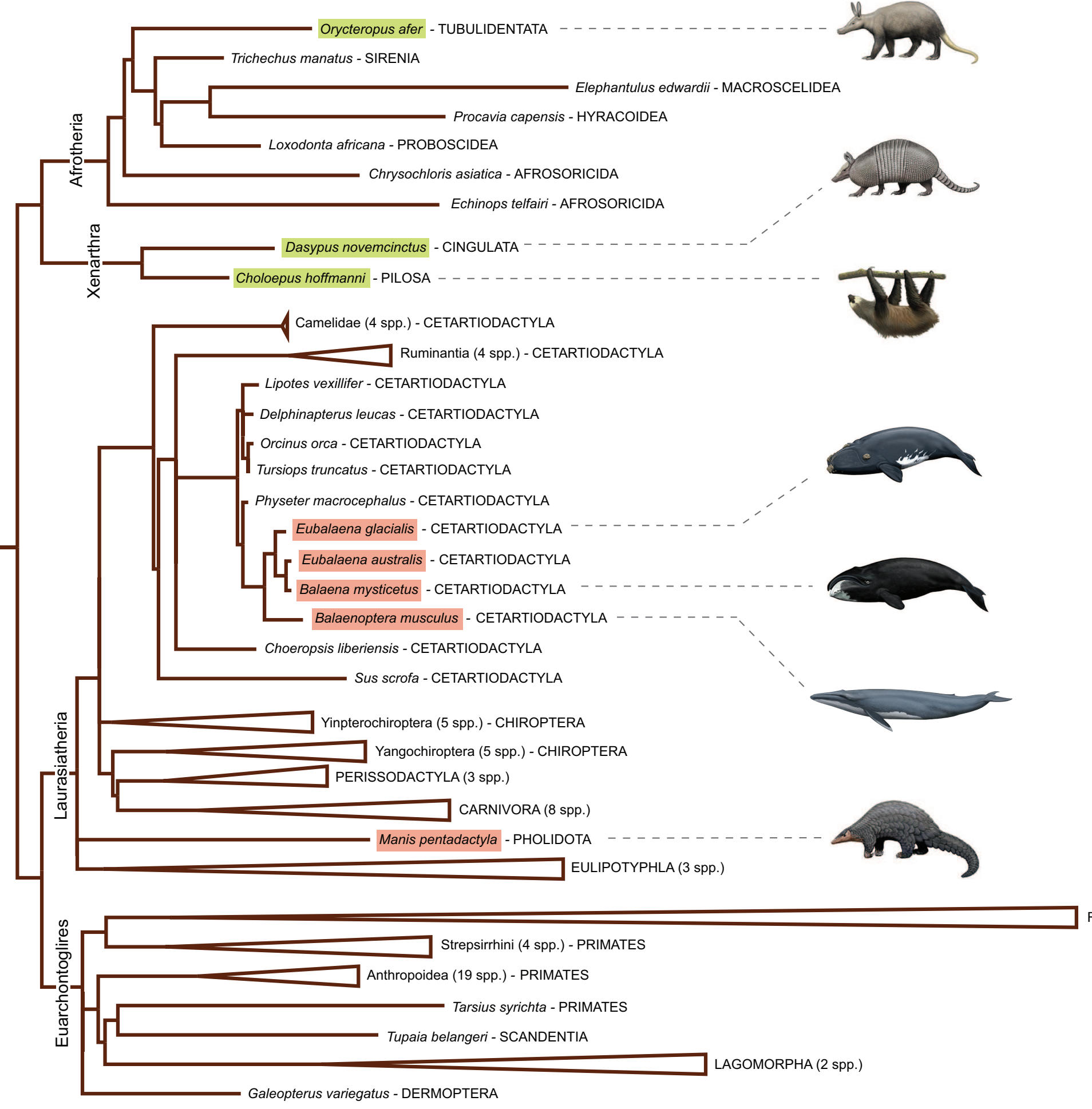

RODENTIA (16 spp.) 
Figure 4
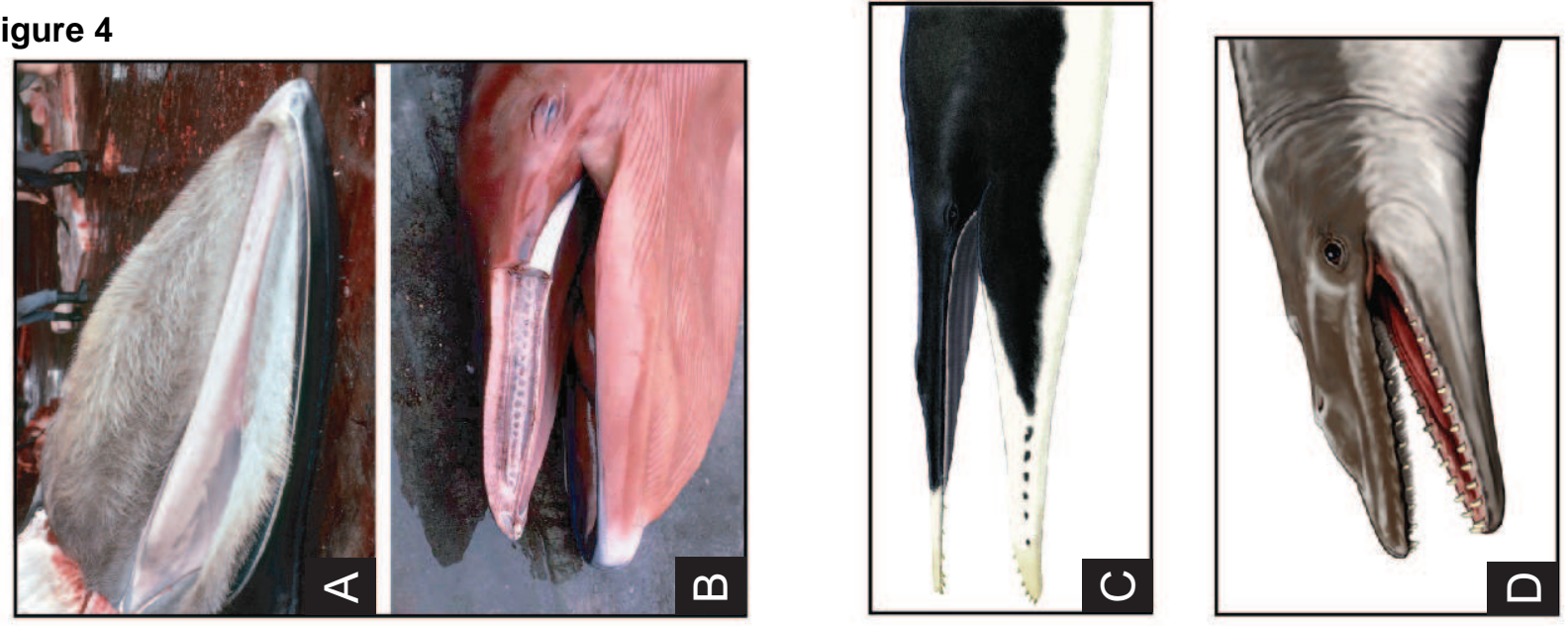

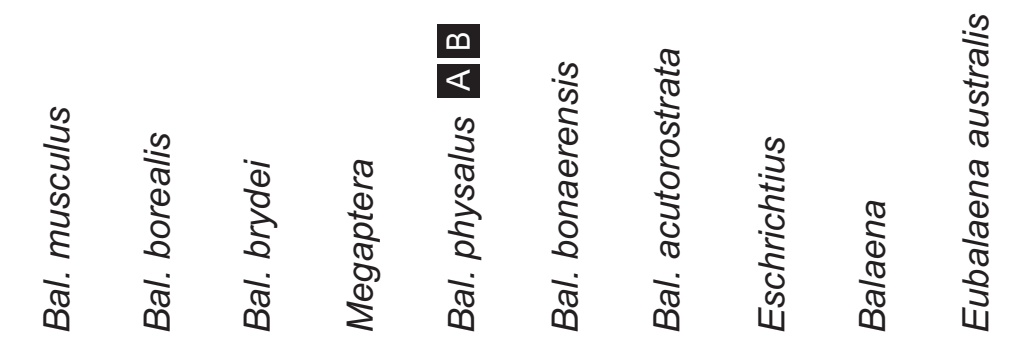
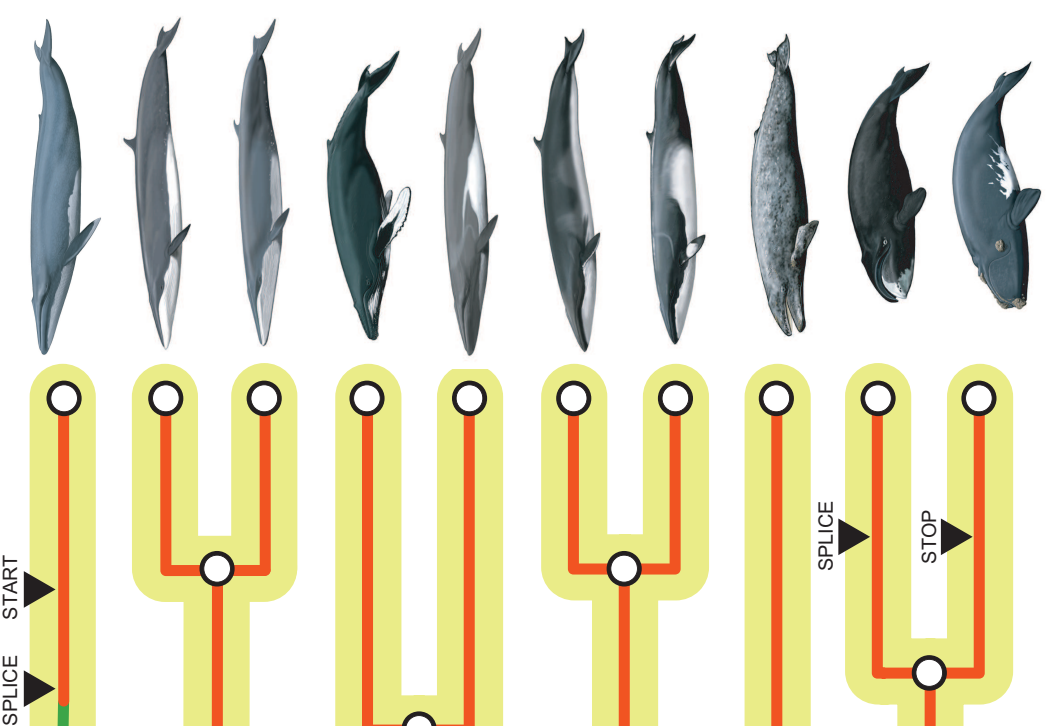

0

0

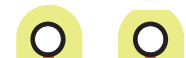

O 0

o 00
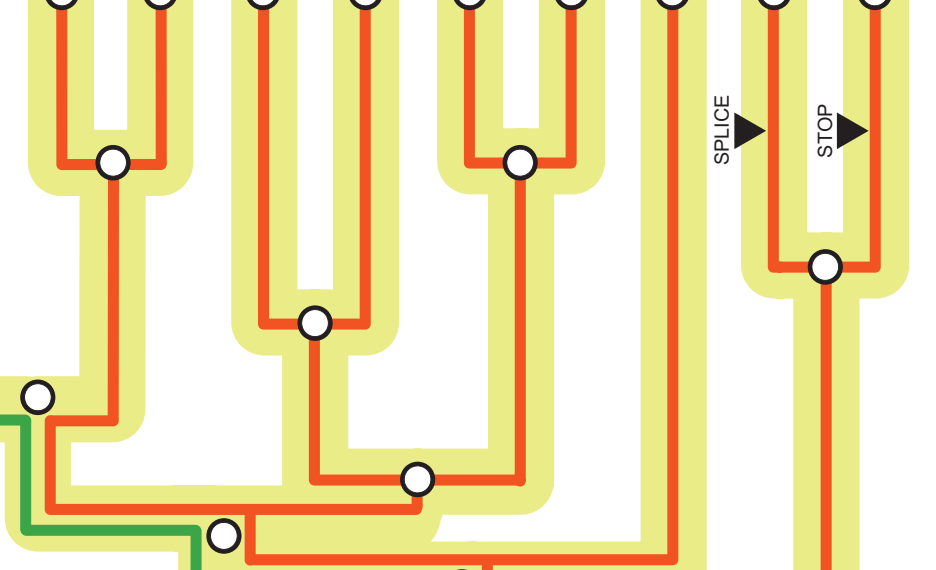

0 
Table 1. Summary of exons that were recovered from genome sequences of edentulous and enamelless mammals for four amelogenesis imperfecta genes ( $C 4$ orf $26, \mathrm{FAM} 83 \mathrm{H}$, SLC24A4, WDR72).

\begin{tabular}{|c|c|c|c|c|}
\hline Taxon & \multicolumn{4}{|c|}{ Gene } \\
\hline $\begin{array}{l}\text { 1. Edentulous } \\
\text { taxa }\end{array}$ & $C 4 \operatorname{orf} 26^{\mathrm{a}}$ & $F A M 83 H$ & SLC24A4 & WDR72 \\
\hline $\begin{array}{c}\text { Manis } \\
\text { pentadactyla } \\
\text { (Chinese } \\
\text { pangolin) }\end{array}$ & $\begin{array}{l}1,3 \text { (both } \\
\text { contain } \\
\text { frameshift } \\
\text { mutations) }\end{array}$ & $1-3,4$ (partial) & $2-17$ & $2-14$ \\
\hline $\begin{array}{c}\text { Balaena } \\
\text { mysticetus } \\
\text { (bowhead } \\
\text { whale) }\end{array}$ & $\begin{array}{l}\text { (start codon } \\
\text { mutation), } 3 \\
\text { (splice site } \\
\text { mutation } \\
\text { adjacent to } \\
\text { exon) }\end{array}$ & $1-4$ & $1-17$ & $2-20$ \\
\hline $\begin{array}{l}\text { Balaenoptera } \\
\text { acutorostrata } \\
\text { (common } \\
\text { minke whale) }\end{array}$ & $\begin{array}{l}\text { Both exons } \\
\text { deleted from } \\
\text { genome }\end{array}$ & $1-3,4$ (partial) & $\begin{array}{c}1-6,7 \text { (partial), } \\
8-17\end{array}$ & $2-20$ \\
\hline $\begin{array}{c}\text { Balaenoptera } \\
\text { bonaerensis } \\
\text { (Antarctic } \\
\text { minke whale) }\end{array}$ & $\begin{array}{l}\text { Both exons } \\
\text { deleted from } \\
\text { genome }\end{array}$ & $1-3,4{\text { (partial })^{b}}^{b}$ & $1-6,8-17$ & $2-20$ \\
\hline $\begin{array}{c}\text { 2. Taxa with } \\
\text { enamelless } \\
\text { teeth }\end{array}$ & & & & \\
\hline $\begin{array}{c}\text { Orycteropus } \\
\text { afer (aardvark) }\end{array}$ & 1,3 & $1-4$ & $1-2,4-17$ & $2-17,19-20$ \\
\hline $\begin{array}{c}\text { Choloepus } \\
\text { hoffmanni } \\
\text { (Hoffmann's } \\
\text { two-toed sloth) }\end{array}$ & 1,3 & $1-4$ & $1-17$ & $2-20$ \\
\hline $\begin{array}{c}\text { Dasypus } \\
\text { novemcinctus } \\
\text { (nine-banded } \\
\text { adrmadillo) }\end{array}$ & 1,3 & $\begin{array}{c}1,2 \text { (partial), } 3, \\
4 \text { (partial) }\end{array}$ & $1-17$ & $\begin{array}{c}3-13,14 \\
\text { (partial), 15, } \\
17-20\end{array}$ \\
\hline
\end{tabular}

${ }^{a}$ C4orf 26 has two exons, 1 and 3, except in catarrhine primates and possibly Oryctolagus cuniculus (see main text) where a third exon (exon 2) is intact and implies expression of a protein that is translated in a different reading frame for exon 3.

${ }^{b}$ Complete coding sequences were recovered for Balaenoptera bonaerensis and its congener, B. physalus, in hybridization capture experiments. 
Table 2. The number of reads assembled to Orcinus orca and Tursiops truncatus reference sequences for three different tooth genes.

\begin{tabular}{|c|c|c|c|c|c|c|}
\hline Gene & Exon(s) & Probe & \multicolumn{4}{|c|}{ Taxon } \\
\cline { 4 - 7 } & & Length & $\begin{array}{c}\text { Choeropsis } \\
\text { liberiensis }\end{array}$ & $\begin{array}{c}\text { Balaenoptera } \\
\text { bonaerensis }\end{array}$ & $\begin{array}{c}\text { Balaenoptera } \\
\text { physalus }\end{array}$ & $\begin{array}{c}\text { Delphinapterus } \\
\text { leucas }\end{array}$ \\
\hline C4orf26\# & 1 & 187 & 8833 & 2 & 0 & 10877 \\
\hline & 3 & 485 & 11332 & 3 & 1 & 19888 \\
\hline ENAM $^{*}$ & 2 & 234 & 7840 & 5270 & 4873 & 18777 \\
\hline & $3+4$ & 355 & 16419 & 9423 & 10084 & 28718 \\
\hline & 5 & 159 & 5320 & 3990 & 4521 & 13260 \\
\hline & 6 & 402 & 11628 & 11484 & 8352 & 15422 \\
\hline & 7 & 186 & 6318 & 3921 & 5038 & 17286 \\
\hline & 8 & 174 & 6492 & 3543 & 4287 & 14564 \\
\hline & 9 & 2968 & 139066 & 75899 & 87471 & 196158 \\
\hline FAM83H\# & 1 & 567 & 14348 & 3535 & 4306 & 10028 \\
\hline & $2+3$ & 495 & 11607 & 2779 & 3194 & 5202 \\
\hline & 4 & 2866 & 42730 & 24228 & 14021 & 31128 \\
\hline
\end{tabular}

*Tursiops probes

\#Orcinus probes 
Table 3. Results of dN/dS analyses with different branch categories and two different codon frequency models ( $\mathrm{CF} 1, \mathrm{CF} 2)$.

\begin{tabular}{|c|c|c|}
\hline \multirow{2}{*}{$\begin{array}{l}\text { Analysis, Number of } \\
\text { Branch Categories, and } \\
\text { Statistical Comparisons }\end{array}$} & \multicolumn{2}{|c|}{$\begin{array}{l}\text { Codon Models, dN/dS Values, Likelihood Scores, and } \\
\text { Statistical Tests }\end{array}$} \\
\hline & CF1 & CF2 \\
\hline \multicolumn{3}{|l|}{$\begin{array}{l}\text { Model 1. One dN/dS } \\
\text { Category }\end{array}$} \\
\hline All branches & 0.5067 & 0.4945 \\
\hline Ln likelihood & -2882.527342 & -2876.962701 \\
\hline \multicolumn{3}{|l|}{$\begin{array}{l}\text { Model 2. Four dN/dS } \\
\text { Categories }\end{array}$} \\
\hline $\begin{array}{l}\text { Branches leading to taxa } \\
\text { with teeth }\end{array}$ & 0.4487 & 0.4384 \\
\hline Pangolin branch & 2.0012 & 1.9501 \\
\hline Stem mysticete branch & 1.7699 & 1.6144 \\
\hline Crown mysticete branches & 0.7307 & 0.7085 \\
\hline Ln likelihood & -2874.884687 & -2869.377094 \\
\hline Model 1 versus Model 2 & $\begin{array}{l}2 \Delta \ln \text { likelihood }=15.28531 \\
\mathrm{p}=0.001588^{\mathrm{C}}(\mathrm{df}=3)\end{array}$ & $\begin{array}{l}2 \Delta \ln \text { likelihood }=15.17121 \\
\mathrm{p}=0.001676^{\mathrm{D}}(\mathrm{df}=3)\end{array}$ \\
\hline \multicolumn{3}{|l|}{$\begin{array}{l}\text { Model 3. Two dN/dS } \\
\text { Categories }\end{array}$} \\
\hline $\begin{array}{l}\text { Branches leading to taxa } \\
\text { with teeth }\end{array}$ & 0.4494 & 0.4390 \\
\hline $\begin{array}{l}\text { Branches for edentulous } \\
\text { taxa (pangolin, mysticetes) } \\
\text { fixed at } 1\end{array}$ & 1.0000 & 1.0000 \\
\hline Ln likelihood & -2876.543221 & -2870.941270 \\
\hline Model 1 versus Model 3 & $\begin{array}{l}2 \Delta \ln \text { likelihood }=11.96824 \\
p=0.0005412^{A}(d f=1)\end{array}$ & $\begin{array}{l}2 \Delta \ln \text { likelihood }=12.04286, \\
p=0.0005199^{B}(d f=1)\end{array}$ \\
\hline Model 2 versus Model 3 & $\begin{array}{l}2 \Delta \ln \text { likelihood }=3.317068 \\
\mathrm{p}=0.190418(\mathrm{df}=2)^{\mathrm{E}}\end{array}$ & $\begin{array}{l}2 \Delta \ln \text { likelihood }=3.128352 \\
\mathrm{p}=0.209260(\mathrm{df}=2)^{\mathrm{E}}\end{array}$ \\
\hline \multicolumn{3}{|l|}{$\begin{array}{l}\text { Model 4. Five dN/dS } \\
\text { Categories }\end{array}$} \\
\hline $\begin{array}{l}\text { Branches leading to taxa } \\
\text { with enamel-capped teeth }\end{array}$ & 0.4638 & 0.4542 \\
\hline $\begin{array}{l}\text { Branches for pangolin, stem } \\
\text { Mysticeti, and crown } \\
\text { Mysticeti fixed at } 1\end{array}$ & 1.0000 & 1.0000 \\
\hline Aardvark & 0.4217 & 0.4035 \\
\hline Sloth & 0.2791 & 0.2689 \\
\hline Armadillo & 0.4031 & 0.3907 \\
\hline
\end{tabular}




\begin{tabular}{|l|l|l|}
\hline Ln likelihood & -2876.086813 & -2870.442303 \\
\hline Model 3 versus Model 4 & $2 \Delta \ln$ likelihood $=0.912816$, & $2 \Delta \ln$ likelihood = 0.997934, \\
& $\mathrm{p}=0.822334(\mathrm{df}=3)$ & $\mathrm{p}=0.801752(\mathrm{df}=3)$ \\
\hline
\end{tabular}

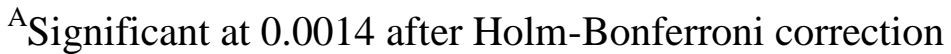
${ }^{\mathrm{B}}$ Significant at 0.0013 after Holm-Bonferroni correction ${ }^{\mathrm{C}}$ Significant at 0.0017 after Holm-Bonferroni correction ${ }^{D}$ Significant at 0.0020 after Holm-Bonferroni correction ${ }^{\mathrm{E}}$ In addition, $\mathrm{dN} / \mathrm{dS}$ values for the pangolin, crown mysticete, and stem mysticete branch categories are not significantly different from 1.0 when each of these categories is fixed at 1 , one at a time, while allowing the other two categories to retain estimated values.
} 
Loss of Tooth Gene C4orf26 in Antarctic Minke Whale

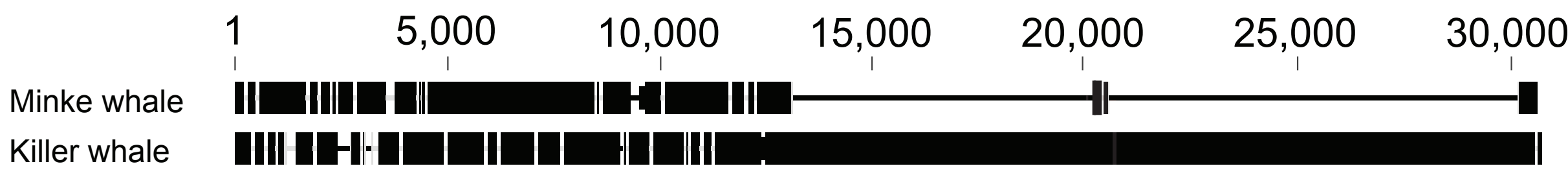
Exon 1
Exon 3 